\title{
Association between the cervicovaginal microbiome, $B R C A 1$ mutation status, and risk of ovarian cancer: a case-control study
}

Nuno R Nené*, Daniel Reisel*, Andreas Leimbach*, Dorella Franchi, Allison Jones, Iona Evans, Susanne Knapp, Andy Ryan, Shohreh Ghazali, John F Timms, Tobias Paprotka, Line Bjørge, Michal Zikan, David Cibula, Nicoletta Colombo, Martin

Widschwendter

${ }^{*}$ Contributed equally and are joint first authors

Department of Women's Cancer, EGA Institute for Women's Health, Faculty of Population Health Sciences, University College London, London, UK

(N R Nené PhD, D Reisel PhD, A Jones BSc, I Evans PhD, S Knapp PhD, A Ryan PhD, S Ghazali MSc, J F Timms DPhil, Prof M Widschwendter MD);

Eurofins Genomics Europe Sequencing, Constance, Germany

(A Leimbach PhD,T Paprotka PhD);

Istituto Europeo di Oncologia, Milan, Italy

(D Franchi MD, Prof N Colombo MD);

Department of Obstetrics and Gynaecology, Haukeland University Hospital, Bergen, Norway

(Prof L Bjørge PhD);

Centre for Cancer Biomarkers, Department of Clinical Science, University of Bergen, Bergen, Norway

(Prof L Bjørge);

Gynaecologic Oncology Center (Prof D Cibula MD) and Department of Gynecology and Obstetrics (Prof M Zikan MD), First Faculty of Medicine, Charles University in Prague, Prague, Czech Republic;

Hospital Na Bulovce, Prague, Czech Republic

(Prof M Zikan);

General University Hospital in Prague, Prague, Czech Republic

(Prof D Cibula);

University of Milano-Bicocca, Milan, Italy

(Prof N Colombo)

Correspondence to: Prof Martin Widschwendter, Department of Women's Cancer, EGA Institute for Women's Health, Faculty of Population Health Sciences, University College London, London WC1E 6AU, UK, m.widschwendter@ucl.ac.uk 


\section{Summary}

\section{Background:}

Various factors - including age, family history, inflammation, reproductive factors, and tubal ligation - modulate the risk of ovarian cancer. In this study, our aim was to establish whether women with, or at risk of developing, ovarian cancer have an imbalanced cervicovaginal microbiome.

\section{Methods:}

We did a case-control study in two sets of women aged 18-87 years in the Czech Republic, Germany, Italy, Norway, and the UK. The ovarian cancer set comprised women with epithelial ovarian cancer and controls (both healthy controls and those diagnosed with benign gynaecological conditions). The BRCA set comprised women with a $B R C A 1$ mutation but without ovarian cancer and controls who were wild type for $B R C A 1$ and $B R C A 2$ (both healthy controls and those with benign gynaecological conditions). Cervicovaginal samples were gathered from all participants with the ThinPrep system and then underwent 16S rRNA gene sequencing. For each sample, we calculated the proportion of lactobacilli species (ie, Lactobacillus crispatus, Lactobacillus iners, Lactobacillus gasseri, and Lactobacillus jensenii), which are essential for the generation of a protective low vaginal $\mathrm{pH}$, in the cervicovaginal microbiota. We grouped samples into those in which lactobacilli accounted for at least $50 \%$ of the species present (community type L) and those in which lactobacilli accounted for less than $50 \%$ of the species present (community type $\mathrm{O}$ ). We assessed the adjusted association between $B R C A 1$ status and ovarian cancer status and cervicovaginal microbiota community type, using a logistic regression model with a bias reduction method. 


\section{Findings:}

Participants were recruited between Jan 2, 2016, and July 21, 2018. The ovarian cancer set $(n=360)$ comprised 176 women with epithelial ovarian cancer, 115 healthy controls and 69 controls with benign gynaecological conditions. The BRCA set $(n=220)$ included 109 women with $B R C A 1$ mutations, 97 healthy controls wild type for $B R C A 1$ and $B R C A 2$ and 14 controls with a benign gynaecological condition wild type for $B R C A 1$ and $B R C A 2$. On the basis of two-dimensional density plots, receiver-operating characteristic curve analysis, and age thresholds used previously, we divided the cohort into those younger than 50 years and those aged 50 years or older. In the ovarian cancer set, women aged 50 years or older had a higher prevalence of community type $\mathrm{O}$ microbiota (81 [61\%] of 133 ovarian cancer cases and 84 [59\%] of 142 healthy controls) than those younger than 50 years (23 [53\%] of 43 cases and 12 [29\%] of 42 controls). In the ovarian cancer set, women younger than 50 years with ovarian cancer had a significantly higher prevalence of community type $\mathrm{O}$ microbiota than did agematched controls under a logistic regression model with bias correction (odds ratio [OR] $2 \cdot 80$ [95\% CI 1.17-6.94]; $\mathrm{p}=0 \cdot 020)$. In the BRCA set, women with BRCA1 mutations younger than 50 years were also more likely to have community type $\mathrm{O}$ microbiota than age-matched controls (OR $2 \cdot 79$ [95\% CI 1·25-6.68]; $p=0 \cdot 012)$, after adjustment for pregnancy (ever). This risk was increased further if more than one firstdegree family member was affected by any cancer (OR 5.26 [95\% CI 1·83-15·30]; $\mathrm{p}=0.0022$ ). In both sets, we noted that the younger the participants, the stronger the association between community type $\mathrm{O}$ microbiota and ovarian cancer or $B R C A 1$ mutation status (eg, OR for community type $\mathrm{O}$ for cases aged $<40$ years in the ovarian cancer set 7·00 [95\% CI 1·27-51·44], p=0·025; OR for community type O for BRCA1 mutation carriers aged $<35$ years in the BRCA set $4 \cdot 40[1 \cdot 14-24 \cdot 36], \mathrm{p}=0 \cdot 031$ ). 


\section{Interpretation:}

The presence of ovarian cancer, or factors known to increase risk for the disease, i.e. age or $B R C A 1$ germline mutations, are significantly associated with a dominant community-type O cervico-vaginal microbiota. Whether re-instatement of communitytype L microbiome, using, for instance, vaginal suppositories containing live lactobacilli, would indeed alter the microbiomial load and composition higher up in the female genital tract, and at the Fallopian Tube, the site of origin of high grade serous ovarian cancer, and whether this would translate into a reduced rate of ovarian cancer, needs to be determined.

Funding:

EU Horizon 2020 Research and Innovation Programme, EU Horizon 2020 European Research Council Programme, and The Eve Appeal.

\section{Introduction}

Evidence is accumulating that microbiota can affect the risk of cancer development, response to oncological therapy, and development of cancer-associated and treatmentrelated complications. ${ }^{1}$ Most of the available evidence so far relates to the gut microbiome $^{2}$, but some data suggest roles for the urinary ${ }^{3}$ and cervicovaginal ${ }^{4}$ microbiomes in the development of bladder and endometrial cancers, respectively. Whether the absence or disruption of the normal protective microbiome-and particularly of the non-gut microbiome - is associated with predisposition to cancer has not been thoroughly investigated. This information is a prerequisite for assessment of the risk associated with dysbiosis and to assess whether restoration of the normal microbiota could help to prevent cancer. 
In addition to age, $B R C A 1$ and $B R C A 2$ germline mutations, parity, oral contraceptive use, and endometriosis, ${ }^{5}$ ascending infections leading to pelvic inflammatory disease ${ }^{6}$ and procedures that theoretically mitigate the risk of ascending infection (ie, tubal ligation) modify the risk of ovarian cancer. The cervicovaginal microbiota is dominated by Lactobacillus crispatus, Lactobacillus iners, Lactobacillus gasseri, or Lactobacillus jensenii, ${ }^{7-9}$ and prevents urogenital disease by lowering the vaginal $\mathrm{pH}$ via lactic acid production and by several other mechanisms, including immunomodulation. ${ }^{10}$ Ravel and colleagues ${ }^{7}$ described four types of Lactobacillus community (groups I, II, III, and $\mathrm{V}$, which are dominated by $L$ crispatus, $L$ gasseri, L iners, and L jensenii, respectively) that - compared with community type IV, which contains higher proportions of strictly anaerobic organisms - are associated with a substantially lower vaginal $\mathrm{pH}$, which could potentially decrease the risk of ascending infection.

\section{Panel: Research in context}

\section{Evidence before this study}

At the initiation of this case-control study, on Sept 15, 2015, we searched PubMed with the terms "[ovarian cancer or $B R C A 1]$ and [cervical or vaginal] and [microbiome or lactobacilli]" for studies published in any language in which the vaginal or cervical microbiome was assessed in women with ovarian cancer or BRCA1 mutations. We also manually searched the reference lists of papers identified by our search. Neither the original search, nor any subsequent searches, the last of which was done on Dec 20, 2018, identified any published studies about this topic. 


\section{Added value of this study}

To our knowledge, this study is the first case-control analysis of the cervicovaginal microbiome in women with ovarian cancer and in women at high risk of ovarian cancer (ie, with a BRCA1 mutation). Our finding that a dysbiosis (ie, a lower proportion of lactobacilli in the cervicovaginal microbiome) is present not only in women younger than 50 years with established ovarian cancer, but also in those at high risk of the disease, supports the view that various factors, including genetic factors, reveal their carcinogenic potential via a modifiable cell non-autonomous mechanism, such as the microbiome.

\section{Implications of all the available evidence}

Although our findings suggest that the cervicovaginal microbiome is implicated in ovarian cancer risk, the causative link between dysbiosis and ovarian cancer has yet to be further assessed. The proportion of lactobacilli should be combined with genetic and epidemiological factors in ovarian cancer risk predicting models. Once the functional relevance of community type $\mathrm{O}$ cervicovaginal microbiota in ovarian cancer development has been established, vaginal lactobacilli transplantation in young carriers of germline $B R C A 1$ mutations could become available as a risk-reduction measure.

\section{Methods}

\section{Study design and participants}

We did a case-control study of the association between cervicovaginal microbiota composition, BRCA1 mutation status, and ovarian cancer status, in two separate datasets, by using 16S rRNA sequencing. The ovarian cancer set comprised women with epithelial ovarian cancer and controls (both healthy controls and those diagnosed 
with benign gynaecological conditions). The BRCA set comprised women with a BRCA1 mutation but without ovarian cancer and controls who were wild type for BRCA1 (both healthy controls and those with benign gynaecological conditions). Our study was part of a multicentre study (the FORECEE [4C] Programme), which was done at 14 recruitment sites in five European countries: the Czech Republic, Germany, Italy, Norway, and the UK (appendix pp 41-42). Participants aged 18-87 years were recruited to our microbiome substudy in three different settings: women with suspected ovarian cancer, benign gynaecological conditions, and women with BRCA1 mutations were recruited from hospitals during outpatient clinics; healthy women from the general population were recruited via routine cervical cancer screening programmes; and both women who were $B R C A 1$ mutation carriers and healthy women were recruited by a dedicated research clinic (through outreach campaigns and public engagement). Eligible ovarian cancer cases were women with a suspected diagnosis of a malignant invasive epithelial ovarian cancer who were recruited before undergoing surgery or receiving any chemotherapy or radiotherapy. Before agreeing to take part, each prospective participant was given a participant information sheet, and the rationale for the study was explained. Additional resources, including an explanatory video and further online resources, were also made available. Before enrolment, prospective participants completed an epidemiological questionnaire (administered via the Qualtrics application on dedicated iPads), comprising questions about current and historical health habits, relevant risk factors, and their medical and obstetric history. All participants provided written informed consent. The FORECEE (4C) Programme received ethical approval from the UK Health Research Authority (REC 14/LO/1633). 


\section{Procedures}

A small group of research midwives or physicians used the ThinPrep system (Hologic, Marlborough, MA, USA) to collect cervical smear samples from all participants at collaborating hospitals and recruitment centres. Briefly, cervical cells were sampled with a Rovers cervix brush (Rovers Medical Devices, Oss, Netherlands), which was inserted into the vagina, rotated fully five times while in contact with the cervix, then removed and immersed in a ThinPrep vial containing PreservCyt fluid (Hologic). The brush was pushed against the bottom of the vial ten times to facilitate release of the cells into the PreservCyt solution, and then discarded. Sample vials were sealed and stored locally at room temperature before shipment to University College London (London, UK) at ambient temperature. All biological samples were assigned anonymous participant identification numbers, which were matched with participants' names in a securely stored link file.

During wet laboratory processing, each cervical smear sample was poured into $50 \mathrm{~mL}$ Falcon tubes (Fisher Scientific, Loughborough, UK) and left to sediment at room temperature for $2 \mathrm{~h} .1 \mathrm{~mL}$ wide-bore tips were used to transfer cervical cell enriched sediment to $2 \mathrm{~mL}$ cryovials, which were stored at $-80^{\circ} \mathrm{C}$. Next-generation sequencing was done on all samples in both sets. Total DNA extraction from cervical smears was done with the QIAsymphony DSP Virus/Pathogen kit (Qiagen, Hilden, Germany) according to the manufacturer's instructions. Sequencing and taxonomical classification of bacterial species in cervical samples was done by Eurofins Genomics Europe Sequencing (Constance, Germany) as previously described. 12 In brief, the hypervariable V1-V3 region of the bacterial small subunit ribosomal DNA (16S rRNA genes) was amplified with primers modified from work by Klindworth and colleagues 
to decrease melting temperature stringency and, as a result, increase taxonomic coverage, including Illumina adapters and dual index barcodes. These barcoded libraries were equimolarly pooled and sequenced on the HiSeq2500 with 300 bp pairedend reads (HiSeq Rapid SBS Kit v2; Illumina, San Diego, CA, USA). The 16S rRNA gene PCRs, next-generation sequencing libraries, and pooled libraries were quality checked by Eurofins Genomics via electropherograms and fluorometer concentration determinations. Additionally, positive and negative controls were included in each library preparation, including DNA extraction batches.

To process the 16S rRNA gene-sequencing data, the demultiplexed sequencing reads were quality checked, trimmed, and filtered with Sickle (version 1.33; settings: -q 20, $1246,-n$ yes), and adapters and primers were removed with Cutadapt (version 1.10; settings: --minimum-length 246). Overlapping paired-end reads were merged for fulllength V1-V3 16S amplicons with FLASH (version 1.2.11; settings: --min-overlap 10, -- maxoverlap 300, --max-mismatch-density $0 \cdot 25)^{14}$ and clustered with CD-HIT (version 4.6; settings: -c 0.99 and cluster filtered, resulting in a minimum number of two members), ${ }^{15}$ and then chimeric sequences were removed with UCHIME (version 4.2.40). ${ }^{16}$ Operational taxonomic units were assigned with BLASTN+ (version 2.4.0; evalue $1 \mathrm{e}-06)^{17}$ via a non-redundant $16 \mathrm{~S}$ rRNA reference database from the Ribosomal Database Project (release 11), ${ }^{18}$ and filtered to ensure that only high-quality operational taxonomic units were included (ie, 97\% identity threshold, 95\% alignment coverage, 376 query length threshold, and 10\% bitscore threshold). Taxonomic classification was based on the US National Center for Biotechnology Information taxonomy. ${ }^{19}$ To 
establish species diversity and evenness, we calculated both the Shannon and the Simpson indices for each sample. ${ }^{7}$

For the purposes of this study, we collapsed Ravel's four Lactobacillus community groups I, II, III, and V into one microbial community, which we referred to as community type L. We divided samples into people whose cervicovaginal microbiota consisted of at least $50 \%$ community type $\mathrm{L}$ and those whose microbiota consisted of less than $50 \%$ community type $\mathrm{L}$, which we referred to as community type O. Generally, community type L microbiota are dominated by a Lactobacillus species, whereas type $\mathrm{O}$ microbiota communities have more bacterial diversity, are composed of typical obligate and facultative anaerobe genera (such as Gardnerella or Atopobium species) and are in turn associated with aerobic vaginitis and bacterial vaginosis. ${ }^{7}$

For control participants in the BRCA set, nextgeneration sequencing of white blood cell DNA (blood samples were taken from all participants in the FORECEE [4C] Programme) was done by Color Genomics (Burlingame, CA, USA) to exclude a germline mutation in $B R C A 1$ and $B R C A 2$. Mutation testing was not done for control participants in the ovarian cancer set.

\section{Statistical analysis}

As part of the FORECEE programme, we estimated that we required 300-400 cases and controls for the ovarian cancer set. The power calculation used to determine the proposed sample sizes was based on methods used to quantify sample size for analyses of DNA methylation. ${ }^{20}$ Because the availability of microbiome data for each participant was part of a concerted effort to establish a multiomics pipeline for women's cancer 
prevention, the same operating characteristics used in the other parts of FORECEE were assumed for the datasets reported here.

Controls were initially matched one to one with cases (ovarian cancer cases or BRCAI mutation carriers) based on menopausal status, age (in 5-year age ranges when possible), and recruitment centre and country.

To classify and identify predictors, we fitted a logistic regression model independently to each covariate in the clinical data collected from each participant in the study, to $B R C A 1$, ovarian cancer, or control status, and to microbiota community status (ie, type $\mathrm{L}$ or type $\mathrm{O}$ ). The covariates leading to a significant association with the outcome (ie, a $\mathrm{p}<0.05$, with the $95 \%$ CI for the calculated odds ratio [OR] not crossing 1) were selected to adjust the prediction performance of $B R C A 1$, ovarian cancer status, and microbiota community type status. We tested both additive models with and without interaction terms. The logistic regression model was implemented in the logistf $\mathrm{R}$ package (version 1.23), which fits a logistic regression model according to Firth's bias reduction method. Reported $95 \%$ CIs and tests were based on the profile penalised log likelihood. Given that the number of samples was larger than the number of predictors, even when adjusted (maximum of six covariates selected), the logistic regression model was stable. Cases with missing values were omitted in each independent fitting, but not across the whole study. Forest plots were created with the forestplot $\mathrm{R}$ package (version 1.9).

Receiver-operator characteristic curve analysis and the Youden's J statistic were used to calculate the optimal age threshold by which to divide the cohorts into separate age 
groups. Abundance patterns within each age group and each microbiota community type were clustered by a hierarchical clustering algorithm, hclust, in R, via the Ward's method. The patterns were scaled column-wise. The species selected for the heatmaps correspond to L crispatus, L iners, L gasseri, or L jensenii (ie, community type L), in addition to those that ranked highest in terms of average abundance across all participants in each set.

To assess whether sample transit times and time to pre-processing affected our results, we did a two-tailed t test (in SPSS, version 25.0.0.1) for the equality of means, in which we compared time from taking of samples to receipt of the samples by University College London, time from taking samples to pre-processing, and time between taking samples and final analysis, between cases and controls, in both datasets. A univariate logistic regression test with either cancer status or mutation status as the response variable and each of the time variables as the sole predictors was also used to confirm the significance of the results. Additionally, we also tested under the logistic regression paradigm the predictive capacity of these times when the response variable was microbiota community type.

\section{Role of the funding source}

The funder of the study had no role in study design, data collection, data analysis, data interpretation, or writing of the report. The corresponding author had full access to all the data in the study and had final responsibility for the decision to submit for publication. 


\section{Results}

Between Jan 2, 2016, and May 28, 2018, we recruited 219 cases with ovarian cancer and 219 age-matched controls, who comprised the ovarian cancer set. Of these participants, 176 cases with epithelial ovarian cancer and 184 controls (115 healthy controls from the general population and 69 controls with benign gynaecological conditions; table 1; appendix p 43) provided sufficient DNA for 16S rRNA gene sequencing. Of the 176 women with ovarian cancer, 119 (68\%) had serous high-grade disease, $15(9 \%)$ had clear cell disease, $16(9 \%)$ had endometrioid disease, $13(7 \%)$ had mucinous disease, and $13(7 \%)$ had serous low-grade disease. 26 women (15\%) had grade 1 ovarian cancer, $14(8 \%)$ had grade 2 disease, and 131 (74\%) had grade 3; five (3\%) were not graded. $66(38 \%)$ had stage I or II disease and $108(61 \%)$ had stage III or IV disease; two (1\%) were not staged.

Between Feb 7, 2016, and July 21, 2018, we recruited 131 cases with a $B R C A 1$ mutation and 131 age-matched controls, who together comprised the BRCA set. We analysed the microbiota of 109 BRCA1 mutation carriers and 111 age-matched controls (97 healthy controls who were wild type for $B R C A 1$, and 14 controls with a benign gynaecological condition wild type for $B R C A 1$ ) who provided sufficient amounts of DNA for the microbiome analyses (table 2; appendix p 43).

Although we had planned to match cases and controls in both the ovarian cancer set and the BRCA set on the basis of menopausal status, age, and recruitment centre and country, because of an imbalance in recruitment of cases and controls at some centres, some cases were matched according to age and menopausal status alone (appendix pp 59-60). 
On the basis of two-dimensional density plots (appendix p 37), receiver-operating characteristic curve analysis, and age thresholds used previously, ${ }^{7}$ we divided the cohorts into two age groups: those younger than 50 years and those aged 50 years or older. The choice of the threshold of 50 years was a compromise between 45 yearsthe upper limit for the recruitment of volunteers reported previously ${ }^{7}$ - and $55 \cdot 2$ years, which was the value determined by fitting a univariate logistic regression model to the controls in the ovarian cancer set with microbiota community type as the response variable and age as the sole predictor. The two-dimensional densities (appendix p 37), for which the sum of percentages of species associated with community type L was plotted against age for all participants overall and in the ovarian cancer and BRCA sets individually, showed that the threshold of 50 years distinguished the peaks associated with very low microbiota community type L percentages.

Of the 360 people in the ovarian cancer set in whom 16S rRNA gene sequencing was done, 275 were aged 50 year or older (133 cases and 142 controls) and 85 were younger than 50 years (43 cases and 42 controls; table 1). 165 (60\%) of the 275 women aged 50 years or older had community type O microbiota, compared with 35 (41\%) of the 85 women younger than 50 years (table 1). 26 (39\%) of 66 patients with stage I or II ovarian cancer, and 45 (42\%) of 108 with stage III or IV ovarian cancer, had community type L microbiota.

In the ovarian cancer set, the mean time from taking of smear samples to delivery of samples to University College London for testing was $13 \cdot 5$ days (SD $11 \cdot 5$; range 0 71), and the mean time from receipt of samples to preprocessing (ie, enrichment and 
storage at $-80^{\circ} \mathrm{C}$ ) was $23 \cdot 5$ days (SD $34 \cdot 0$; range $0-434$ days). A t test showed that neither time from collection to receipt $(\mathrm{p}=0 \cdot 66)$ nor time from receipt to pre-processing $(p=0 \cdot 12)$ differed significantly between cases and controls.

In the BRCA set, the mean time from collection of samples to receipt was $10 \cdot 8$ days (SD 9.2; range 0-38 days), and from receipt of samples to pre-processing was $39 \cdot 5$ days (SD 40·2; range 0-118). Time from collection to receipt did not differ between cases and controls $(p=0 \cdot 16)$, but time from receipt to pre-processing was shorter in cases with the BRCA1 mutation than in controls (24.7 days [SD 30.5] vs $54 \cdot 2$ days [43.3]; $\mathrm{p}<0 \cdot 0001)$. However, when time from receipt to preprocessing was taken individually as a predictor of community type $\mathrm{L}$ or type $\mathrm{O}$ in a logistic regression model in the BRCA set, the results were not significant $(\mathrm{p}=0.86$ and $\mathrm{p}=0.49$ for time from collection to receipt in those younger than 50 years and those aged 50 years or older, respectively; $p=0.68$ and $p=0.71$ for time from receipt to pre-processing in those younger than 50 years and those aged 50 years or older, respectively). Additionally, when time from collection to receipt and time from receipt to pre-processing were combined, the total time from sample collection to pre-processing differed significantly between cases with BRCA1 mutations and controls ( $\mathrm{p}=0 \cdot 0002$; data not shown). However, in the univariate logistic regression we did to confirm these results, the difference was no longer significant $(\mathrm{p}=0.64$ for participants younger than 50 years and $p=0.592$ for those aged 50 years or older).

The most important factor associated with a microbiota characterised by type $\mathrm{L}$ communities in the overall ovarian cancer set was age $(p<0 \cdot 0001)$, followed by menopausal status ( $\mathrm{p}=0 \cdot 0002$; data not shown). 
For the logistic regression model, values were missing only for epidemiological or clinical covariates; these participants were omitted (in each independent fitting, but not across the whole study) because they corresponded to a very small proportion for each variable (maximum $8 \cdot 2 \%$; appendix p 59).

With regard to the prevalence of community type $\mathrm{L}$ and type $\mathrm{O}$ microbiota, in the ovarian cancer set, women with benign gynaecological conditions and healthy volunteers did not differ according to a logistic regression model ( $\mathrm{p}=0 \cdot 49$ for women younger than 50 years and $p=0.97$ for those aged 50 years or older). The corresponding $\mathrm{p}$ values were 0.99 and $0 \cdot 32$, respectively, in the BRCA set.

In women younger than 50 years in the ovarian cancer set, the only factor that was significantly predictive of microbiota community status was the presence or absence of ovarian cancer: cases with ovarian cancer had a significantly increased prevalence of community type $\mathrm{O}$ microbiota than did age-matched controls (odds ratio [OR] $2 \cdot 80$ [95\% CI 1·17-6.94], p=0.020; figure 1A; appendix pp 44-45). Conversely, in women younger than 50 years, several factors were significantly predictive of ovarian cancer status. In addition to current use of the oral contraceptive pill (OCP), duration of OCP use, ever use of hormone replacement therapy, current combined hormone use, and duration of combined hormone use, group community type was significantly predictive of ovarian cancer status, and remained significant after adjustment for additional covariates (OR 2.84 [95\% CI 1·16-11·23]; $\mathrm{p}=0 \cdot 023$; figure 1B; appendix $\mathrm{p} 47$ ). Both purely additive models and those with interaction terms were tested. Here, we report 
the additive models because only these showed significant results (data not shown for models with interaction terms).

In women aged 50 years or older in the ovarian cancer set, there was a tendency towards a higher prevalence of type $\mathrm{O}$ communities than type $\mathrm{L}$ communities in the cervicovaginal samples (table 1). Women who had been on the OCP for more than 5 years or on combined hormones for more than 5 years were more likely to have community type $\mathrm{L}$ microbiota than type $\mathrm{O}$ microbiota, and had a lower risk of developing ovarian cancer than those who had been on the OCP or using combined hormones for less than 5 years (figure 1C, 1D; appendix pp 47-48). The only additional factor that was significantly predictive of community status in women aged 50 years or older was postmenopausal status (which was predictive of community type $\mathrm{O}$ microbiota status; figure 1C) and the only additional factors predictive of ovarian cancer status in these patients were current smoking, ever pregnant, and ever use of hormone replacement therapy (figure 1D).

We assessed whether a type $\mathrm{O}$ cervicovaginal microbiota community was associated with an ovarian cancer predisposition in the 109 age-matched $B R C A 1$ mutation carriers and 111 age-matched controls who had available microbiome data. In this BRCA set, there was a higher preponderance of a type $\mathrm{O}$ cervicovaginal microbiota community in women aged 50 years or older, whereas most of the women aged younger than 50 years had a type L microbiota community (table 2). In women younger than 50 years, both pregnancy (ever) and the presence of the BRCAl mutation were associated with an increased prevalence of community type $\mathrm{O}$ microbiota (figure $2 \mathrm{~A}$ ). After adjustment for pregnancy, the OR for having cervicovaginal microbiota dominated by community 
type O was $2 \cdot 79(95 \%$ CI $1 \cdot 25-6 \cdot 68 ; \mathrm{p}=0 \cdot 012)$ in $B R C A 1$ mutation carriers compared with those who did not have this mutation (figure 2A; appendix pp 49-50).

In the BRCA set, $34 B R C A 1$ mutation carriers had more than one first-degree family member who had been affected by any cancer-a condition that further increases the future likelihood of developing ovarian cancer by 1.8 times. $^{21}$ The OR for having a community type O microbiota was $5 \cdot 26(95 \%$ CI $1 \cdot 83-15 \cdot 30 ; p=0 \cdot 0022)$ in these 34 women compared with those without a BRCA1 mutation (figure 2A). The BRCA set included 45 women younger than 30 years of age, of whom 22 were mutation carriers and 23 were controls. Six $(27 \%)$ of the 22 with a BRCA1 mutation had microbiota dominated by community type $\mathrm{O}$, compared with none of the women without the mutation.

Among women younger than 50 years in the BRCA set, microbiota community type was the only significant predictor of $B R C A 1$ mutation status: the OR for being a $B R C A 1$ mutation carrier was $2 \cdot 84(95 \%$ CI $1 \cdot 29-6 \cdot 69 ; p=0 \cdot 0090)$ in women with community type $\mathrm{O}$ microbiota compared with those with type $\mathrm{L}$ microbiota (figure $2 \mathrm{~B}$; appendix $\mathrm{p}$ 51). Among the 40 women who were aged 50 years or older in the BRCA set, we noted no significant associations between clinical variables and community type or BRCA1 mutation status (figure 2C, 2D; appendix pp 52-53).

Finally, we assessed whether the association between community type $\mathrm{O}$ microbiota and ovarian cancer or BRCA1 mutation status depended on our chosen age cutoff. To this end, the analyses for each of the covariates collected for this study were repeated in both the ovarian cancer and BRCA sets with cutoffs of 40 years, 45 years, and 55 
years (appendix pp 54-58), and additionally with a cutoff of 35 years for the BRCA set, which had sufficient numbers of cases and controls in this age group (appendix $p$ 55). In both sets, the lower the age threshold, the stronger the association in the younger age group between community type $\mathrm{O}$ microbiota and ovarian cancer status (figure $3 \mathrm{~A}$ ) or $B R C A 1$ mutation status (figure 3B).

\section{Discussion}

In this study, we showed that the prevalence of women with non-lactobacilli-dominated cervicovaginal microbiomes was higher both in patients with ovarian cancer and in women with BRCA1 mutations who had yet to develop cancer, compared with agematched healthy women and women without BRCA1 or BRCA2 mutations, respectively.

To assess the cervicovaginal microbiome in these participants, we chose to specifically collect cervicovaginal samples (as opposed to vaginal samples, which are rather similar $^{22}$ ) because we wanted to assess samples from an easy-to-access anatomical area that serves as a barrier for ascending infections affecting the fallopian tube (ie, the organ from which ovarian cancer originates). The rationale for the division of the samples into two age groups - those younger than 50 years and those aged 50 years or olderwas premised on two considerations. In previous work, only volunteers younger than the so called reproductive age—ie, 45 years—-were recruited. ${ }^{7}$ Had we used age 45 years as the cutoff for the ovarian cancer set, the number of ovarian cancer cases included would have been lower, because the disease is more prevalent in older women than in those younger than 45 years. Conversely, in several studies, ${ }^{8,9,23}$ the loss of 
Lactobacillus species from the cervicovaginal microbiota - and, consequently, an increase of community type $\mathrm{O}$ microbiota — was associated with decreases in oestrogen concentrations in postmenopausal women (in association with glycogen decreases). Indeed, in our ovarian cancer set, the higher prevalence of older than younger women with community type $\mathrm{O}$ microbiota is consistent with previous reports. ${ }^{7}$ In view of the challenges associated with the design of a protocol for diseases that are more prevalent in one specific age group than in others (as shown by Walther-Antonio and coworkers $^{4}$ ), we chose an age-matched design for our study. Nevertheless, a division of the cohort into age groups was still necessary to avoid the strong confounding effect of age as a major contributor to ovarian cancer and the microbiome.

Our data suggest that the presence of ovarian cancer or factors known to increase the risk of ovarian cancer (ie, older age or $B R C A 1$ germline mutation) are associated with the absence of a protective community type L cervicovaginal microbiota. The finding that the prevalence of community type L microbiota was lower in patients with ovarian cancer than in healthy controls, irrespective of disease stage, suggests that this reduced prevalence of type L microbiota could be causal rather than consequential. Although our data provide no direct proof that community type $\mathrm{O}$ microbial species dominance (and thereby a potential reduced protection from ascending infections) has a causal role in the development of ovarian cancer, several previously reported findings potentially support this hypothesis. First, an analysis ${ }^{24}$ of the microbiota of ovarian cancer tissue samples and matched non-cancerous tissue showed that two bacterial phyla, namely Proteobacteria and Firmicutes, were predominant in the cancer samples but not in the control samples. Second, inflammation caused by such agents as Proteobacteria and Firmicutes, and the subsequent release of bacterial toxins such as colibactin and 
cytolethal distending toxin, could directly damage the cellular DNA by causing doublestranded breaks and thereby activating the DNA damage checkpoint pathway. ${ }^{25}$ Third, the protective mechanism of interventions that reduce ovarian cancer risk could be mediated, at least partly, by modulation of the microbiota. Tubal ligation ${ }^{26}$ could potentially limit access of ascending bacteria to the fallopian tube and ovaries. Longterm use of a combined OCP could reduce the risk of ovarian cancer ${ }^{27}$ by supporting the colonisation of the vagina with beneficial lactic-acid-producing lactobacilli. ${ }^{28}$ In our study, the finding that in women aged 50 years or older, use of the OCP for more than 5 years is associated with community type L microbiota and reduced risk of ovarian cancer raises the question of whether long-term use of the OCP could be associated with a delay in age-triggered predominance of community type $\mathrm{O}$ in the cervicovaginal microbiota. Whether the association between long-term OCP use and beneficial cervicovaginal microbiota in women aged 50 years or older is merely a surrogate marker for reduced disease risk or whether OCP use has a causal effect on the preservation of a beneficial cervicovaginal microbiota, which in turn protects against ovarian cancer, remains to be established.

Several lines of additional evidence support the view that, in BRCA1 mutation carriers, cell-non-autonomous (systemic) factors trigger the growth of community type $\mathrm{O}$ species in the vagina. We have previously shown that $B R C A 1$ or $B R C A 2$ mutation carriers have increased concentrations of progesterone during the luteal phase of their menstrual cycles. ${ }^{29}$ Vaginal lactobacilli metabolise glucose and maltose- the breakdown products of human glycogen (which is substantially reduced in postmenopausal women) - through fermentation, thereby producing lactic acid. ${ }^{8}$ Progesterone is known to reduce vaginal glycogen concentrations, resulting in an 
environment that is less conducive to the growth of community type L species. Thus, the reduced prevalence of community type L cervicovaginal microbiota in both women with ovarian cancer and $B R C A 1$ mutation carriers younger than 50 years without a diagnosis of ovarian cancer could possibly be a reflection of an accumulating progesterone- oestrogen imbalance.

Our study has several potential limitations. Most of the women included were white. The microbiome (both in general and specifically the vaginal microbiome) ${ }^{7}$ varies substantially by ethnicity ${ }^{30}$ and region, ${ }^{31}$ and therefore our analyses should be repeated in additional cohorts. Another possible limitation is that we did not test people in the ovarian cancer set for BRCA germline mutations. However, given that only $10-12 \%$ of women diagnosed with invasive ovarian cancer have germline mutations in BRCAl or $B R C A 2,{ }^{32}$ it is unlikely that the presence of mutations would have inflated the ORs substantially. As is the case in most studies involving biosamples, the time between sample collection and processing varied among patients. However, all samples were directly transferred to PreservCyt media (which is designed to preserve cellular and subcellular components and prevent microbial growth), and neither the transit time nor the time to pre-processing had any effect on composition of the microbiota community. Thus, it is unlikely that a storage-triggered bias could have substantially affected our results.

In summary, we found that community type $\mathrm{O}$ bacterial compositions dominate the cervicovaginal microbiota in women aged 50 years or older. Furthermore, the presence of ovarian cancer or a germline BRCAl mutation favoured a composition of the cervicovaginal microbiota (ie, a type $\mathrm{O}$ community) that is more commonly seen in 
older than in younger women. Although our findings provide no direct evidence that this seemingly premature ageing of the cervicovaginal microbiome is causally involved in the genesis of ovarian cancer, evidence showing an altered microbiome in ovarian cancer samples compared with control fallopian tube samples ${ }^{33}$ appears to support this line of reasoning. Our findings warrant further detailed analyses of the vaginal microbiome, especially in high-risk women (ie, with BRCA1 mutation) younger than 50 years, and in women with community type $\mathrm{O}$ microbiota (particularly young white women). However, before a clinical trial is initiated, our findings need to be further validated, and longitudinal assessments of the microbiome in mutation carriers will be essential. The application of vaginal suppositories containing a combination of live lactobacilli and oestriol normalises the vaginal microbiota. ${ }^{34}$ Establishing whether a continuous community type L cervicovaginal microbiome could reduce the risk of ovarian cancer should be a priority for further studies in this area.

\section{Contributors}

MW conceived and designed the study, and drafted the article. NRN did the statistical analyses, produced the figures, and interpreted the data in collaboration with MW. AL and TP did the DNA extraction and sequenced the microbiomes. All other authors contributed to data acquisition and interpretation, and critically reviewed and approved

\section{Declaration of interests}

$\mathrm{AL}$ and TP are employees of Eurofins, which offers 16S rRNA gene sequencing as a service. NC reports personal fees from Roche, Pharmamar, AstraZeneca, Clovis, Tesaro, Pfizer, Takeda, and Biocad . All other authors declare no competing interests. 


\section{Data sharing}

The original data including all clinical, epidemiological, and microbiota data used in this work will be made available upon request. Requests should be directed to the corresponding author.

\section{Acknowledgements}

This study was funded by the EU's Horizon 2020 Research and Innovation Programme (H2020 FORECEE under grant agreement 634570), the EU's Horizon 2020 European Research Council Programme (H2020 BRCA-ERC under grant agreement 742432), and The Eve Appeal. We thank the participants of the FORECEE and BRCA-ERC studies; the management team, research nurses, interviewers, research assistants, and other staff who gathered data for this study; Nadine Mall for technical assistance in the microbiome analyses; Karin Sundström for critical revision of the Article; Emma Crosbie, Ranjit Manchanda, Claire Newton, and Nadia Harbeck for help with recruitment of volunteers; and the UK National Institute for Health Research (NIHR) and the University College London Hospitals Biomedical Research Centre.

\section{References}

1 Garrett WS. Cancer and the microbiota. Science 2015; 348: 80-86.

2 McQuade JL, Daniel CR, Helmink BA, Wargo JA. Modulating the microbiome to improve therapeutic response in cancer. Lancet Oncol 2019; 20: e77-91.

3 Bucevic V, Situm M, Chow CT, Chan LS, Roje B, Terzic J. The urinary microbiome associated with bladder cancer. Sci Rep 2018; 8: 12157.

4 Walther-Antonio MR, Chen J, Multinu F, et al. Potential contribution of the uterine microbiome in the development of endometrial cancer. Genome Med 2016; 8: 122. 
5 Jayson GC, Kohn EC, Kitchener HC, Ledermann JA. Ovarian cancer. Lancet 2014; 384: $1376-88$.

6 Lin $\mathrm{H}-\mathrm{W}$, Tu Y-Y, Lin SY, et al. Risk of ovarian cancer in women with pelvic inflammatory disease: a population-based study. Lancet Oncol 2011; 12: 900-04.

7 Ravel J, Gajer P, Abdo Z, et al. Vaginal microbiome of reproductive age women. Proc Natl Acad Sci USA 2011; 108 (suppl 1): 4680-87.

8 Smith SB, Ravel J. The vaginal microbiota, host defence and reproductive physiology. J Physiol 2017; 595: 451-63.

9 van de Wijgert JH, Borgdorff H, Verhelst R, et al. The vaginal microbiota: what have we learned after a decade of molecular characterization? PLoS One 2014; 9: e105998.

10 Reid G. Cervicovaginal microbiomes - threats and possibilities. Trends Endocrinol Metab 2016; 27: 446-54.

11 Mavaddat N, Peock S, Frost D, et al. Cancer risks for $B R C A 1$ and $B R C A 2$ mutation carriers: results from prospective analysis of EMBRACE. J Natl Cancer Inst 2013; 105: 812-22.

12 Mahe F, Mayor J, Bunge J, et al. Comparing high-throughput platforms for sequencing the V4 region of SSU-rDNA in environmental microbial eukaryotic diversity surveys. J Eukaryot Microbiol 2015; 62: 338-45.

13 Klindworth A, Pruesse E, Schweer T, et al. Evaluation of general 16S ribosomal RNA gene PCR primers for classical and next-generation sequencing-based diversity studies. Nucleic Acids Res 2013; 41: e1.

14 Magoc T, Salzberg SL. FLASH: fast length adjustment of short reads to improve genome assemblies. Bioinformatics 2011; 27: 2957-63.

$15 \mathrm{Li} \mathrm{W}$, Godzik A. Cd-hit: a fast program for clustering and comparing large sets of protein or nucleotide sequences. Bioinformatics 2006; 22: 1658-59.

16 Edgar RC, Haas BJ, Clemente JC, Quince C, Knight R. UCHIME improves sensitivity and speed of chimera detection. Bioinformatics 2011; 27: 2194-200.

17 Altschul SF, Gish W, Miller W, Myers EW, Lipman DJ. Basic local alignment search tool. J Mol Biol 1990; 215: 403-10.

18 Cole JR, Wang Q, Cardenas E, et al. The Ribosomal Database Project: improved alignments and new tools for rRNA analysis. Nucleic Acids Res 2009; 37: D141-45.

19 Federhen S. The NCBI taxonomy database. Nucleic Acids Res 2012; 40: D136-43.

20 Pawitan Y, Michiels S, Koscielny S, Gusnanto A, Ploner A. False discovery rate, sensitivity and sample size for microarray studies. Bioinformatics 2005; 21: 3017-24. 
21 Kuchenbaecker KB, Hopper JL, Barnes DR, et al. Risks of breast, ovarian, and contralateral breast cancer for $B R C A 1$ and $B R C A 2$ mutation carriers. JAMA 2017; 317 : 2402-16.

22 Chen $\mathrm{C}$, Song $\mathrm{X}$, Wei W, et al. The microbiota continuum along the female reproductive tract and its relation to uterine-related diseases. Nat Commun 2017; 8: 875.

23 Brotman RM, Shardell MD, Gajer P, et al. Interplay between the temporal dynamics of the vaginal microbiota and human papillomavirus detection. J Infect Dis 2014; 210 : $1723-33$.

24 Banerjee S, Tian T, Wei Z, et al. The ovarian cancer oncobiome. Oncotarget 2017; 8: $36225-45$.

25 Mert I, Walther-Antonio M, Mariani A. Case for a role of the microbiome in gynecologic cancers: clinician's perspective. J Obstet Gynaecol Res 2018; 44: 1693704.

26 Cibula D, Widschwendter M, Majek O, Dusek L. Tubal ligation and the risk of ovarian cancer: review and meta-analysis. Hum Reprod Update 2011; 17: 55-67.

27 Beral V, Doll R, Hermon C, Peto R, Reeves G. Ovarian cancer and oral contraceptives: collaborative reanalysis of data from 45 epidemiological studies including 23257 women with ovarian cancer and 87303 controls. Lancet 2008; 371: 303-14.

28 Brooks JP, Edwards DJ, Blithe DL, et al. Effects of combined oral contraceptives, depot medroxyprogesterone acetate and the levonorgestrel-releasing intrauterine system on the vaginal microbiome. Contraception 2017; 95: 405-13.

29 Widschwendter M, Rosenthal AN, Philpott S, et al. The sex hormone system in carriers of BRCA1/2 mutations: a case-control study. Lancet Oncol 2013; 14: 1226-32.

30 Gaulke CA, Sharpton TJ. The influence of ethnicity and geography on human gut microbiome composition. Nat Med 2018; 24: 1495-96.

$31 \mathrm{He} \mathrm{Y,} \mathrm{Wu} \mathrm{W,} \mathrm{Zheng} \mathrm{HM,} \mathrm{et} \mathrm{al.} \mathrm{Regional} \mathrm{variation} \mathrm{limits} \mathrm{applications} \mathrm{of} \mathrm{healthy} \mathrm{gut}$ microbiome reference ranges and disease models. Nat Med 2018; 24: 1532-35.

32 Risch HA, McLaughlin JR, Cole DE, et al. Prevalence and penetrance of germline $B R C A 1$ and $B R C A 2$ mutations in a population series of 649 women with ovarian cancer. Am J Hum Genet 2001; 68: 700-10.

33 Zhou B, Sun C, Huang J, et al. The biodiversity composition of microbiome in ovarian carcinoma patients. Sci Rep 2019; 9: 1691.

34 Ozkinay E, Terek MC, Yayci M, Kaiser R, Grob P, Tuncay G. The effectiveness of live lactobacilli in combination with low dose oestriol (Gynoflor) to restore the vaginal flora after treatment of vaginal infections. BJOG 2005; 112: 234-40. 


\section{Figure legends}

Figure 1 Effect of selected covariates on microbiota community type and risk of ovarian cancer in the ovarian cancer set. (A) Prediction of microbiota community type in participants younger than 50 years. (B) Prediction of ovarian cancer in participants younger than 50 years. (C) Prediction of microbiota community type in participants aged 50 years or older. (D) Prediction of ovarian cancer in participants aged 50 years or older. Arrows represent truncated 95\% CIs. More data are presented in the appendix ( $p$ p 44-48). $\mathrm{OR}=$ odds ratio. $\mathrm{BMI}=$ body-mass index. $\mathrm{OCP}=$ oral contraceptive pill. HRT=hormone replacement therapy. Community-type $\mathrm{O}$ (adj.), adjusted for current OCP use, duration of OCP use, HRT use (ever), current combined hormone use, and duration of combined hormone use. 

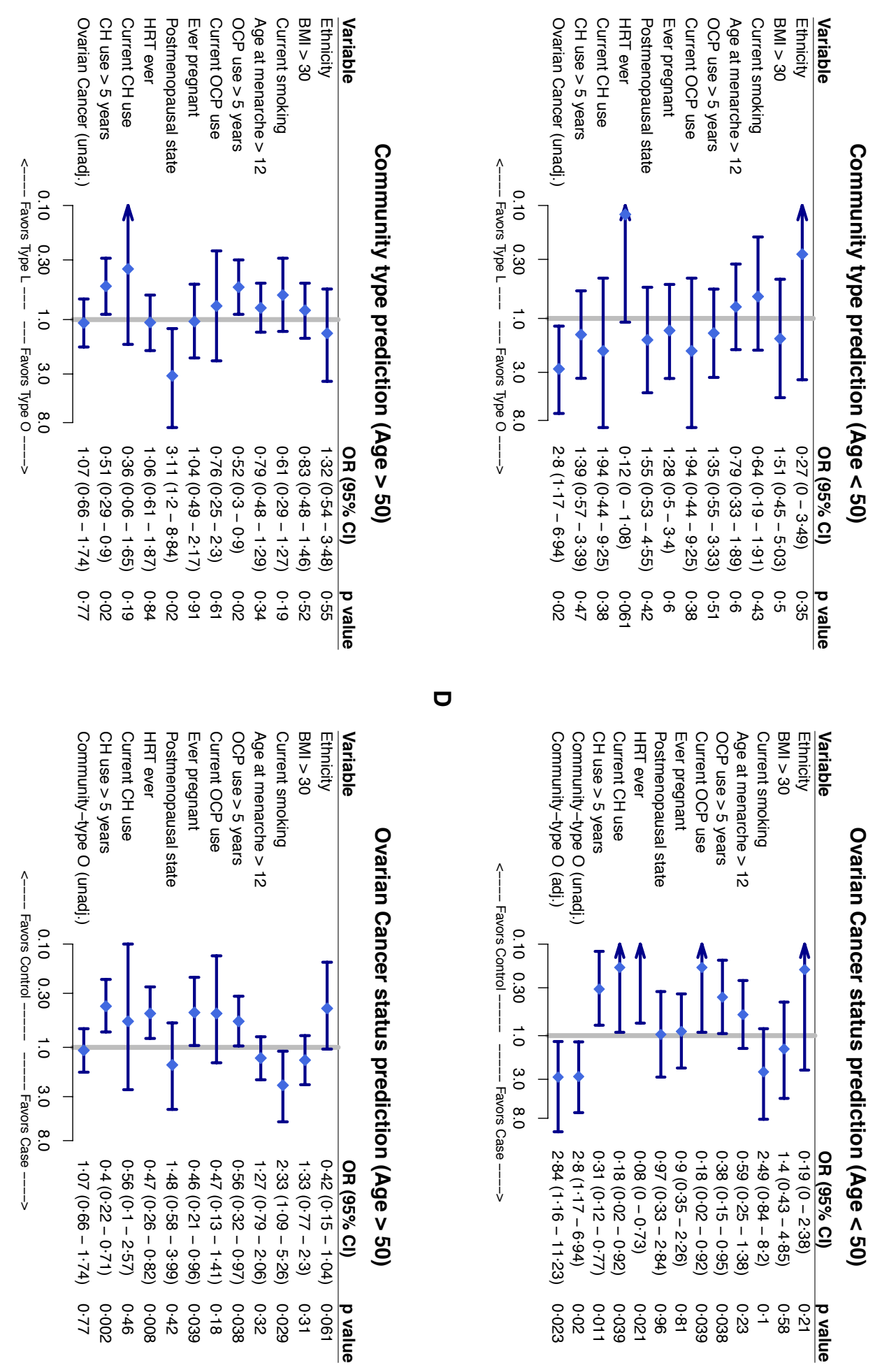
Figure 2 Effect of selected covariates on microbiota community type and risk of BRCA1 mutation in the BRCA set. (A) Prediction of microbiota community type in participants younger than 50 years. Mutation(adj.), adjusted for pregnancy (ever). Mutation $>1$, individuals with wild-type or mutated $B R C A 1$ who have more than one first-degree relative affected by any cancer. (B) Prediction of BRCA1 mutation in participants younger than 50 years. Community-type $\mathrm{O}$ (adj.), adjusted for postmenopausal state (appendix p 51). (C) Prediction of microbiota community type in participants aged 50 years or older. (D) Prediction of $B R C A 1$ mutation in participants aged 50 years or older. Arrows represent truncated 95\% CIs. More data are presented in the appendix ( $\mathrm{pp}$ 49-53). $\mathrm{OR}=$ odds ratio. $\mathrm{BMI}=$ body-mass index. $\mathrm{OCP}=$ oral contraceptive pill. $\mathrm{HRT}=$ hormone replacement therapy. 

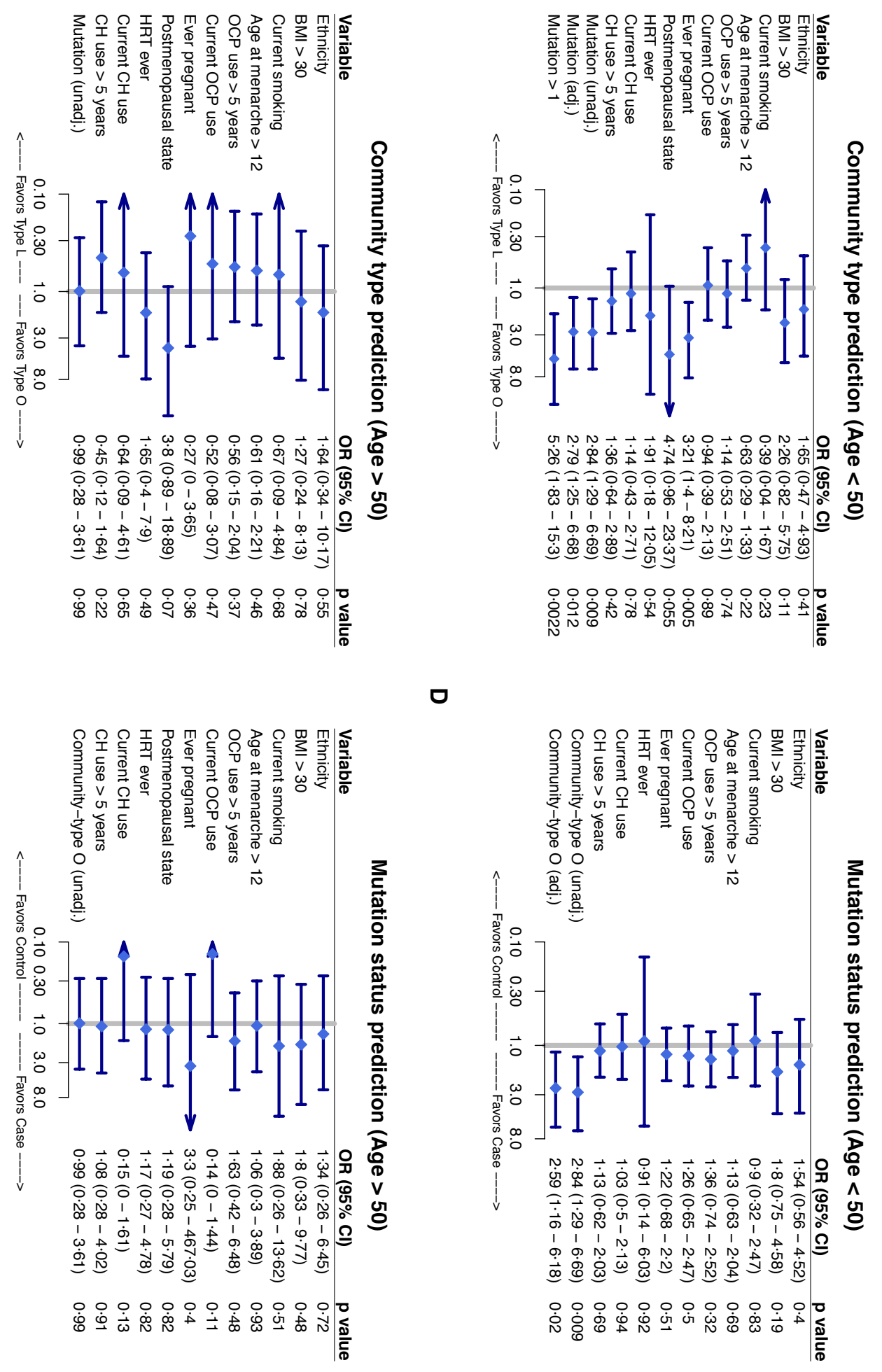
Figure 3. Prediction of microbiota community type for different age thresholds in the ovarian cancer set with ovarian cancer status as predictor. (A), and in the BRCA set with mutation status as the predictor (B) Arrows represent truncated 95\% CIs. More data are presented in the appendix (pp 54-58). $\mathrm{OR}=$ odds ratio.
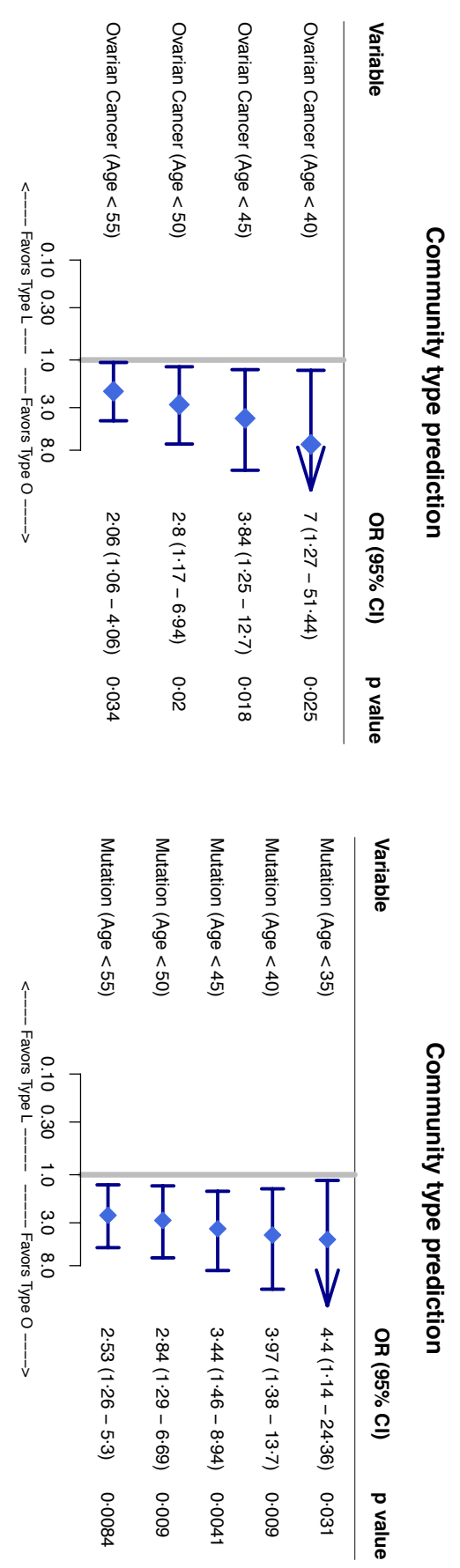


\section{Tables}

\section{Table 1. Descriptive characteristics of cases and controls in the ovarian cancer set}

for all covariates used in prediction models. We calculated $\mathrm{p}$ values under a logistic regression model with a bias reduction method. The appendix shows baseline characteristics for hospital-based controls with benign gynaecological conditions ( $p$ 43) and missing values per covariate ( $\mathrm{p} 59) . \mathrm{OCP}=$ oral contraceptive pill. $\mathrm{HRT}=$ hormone replacement therapy.

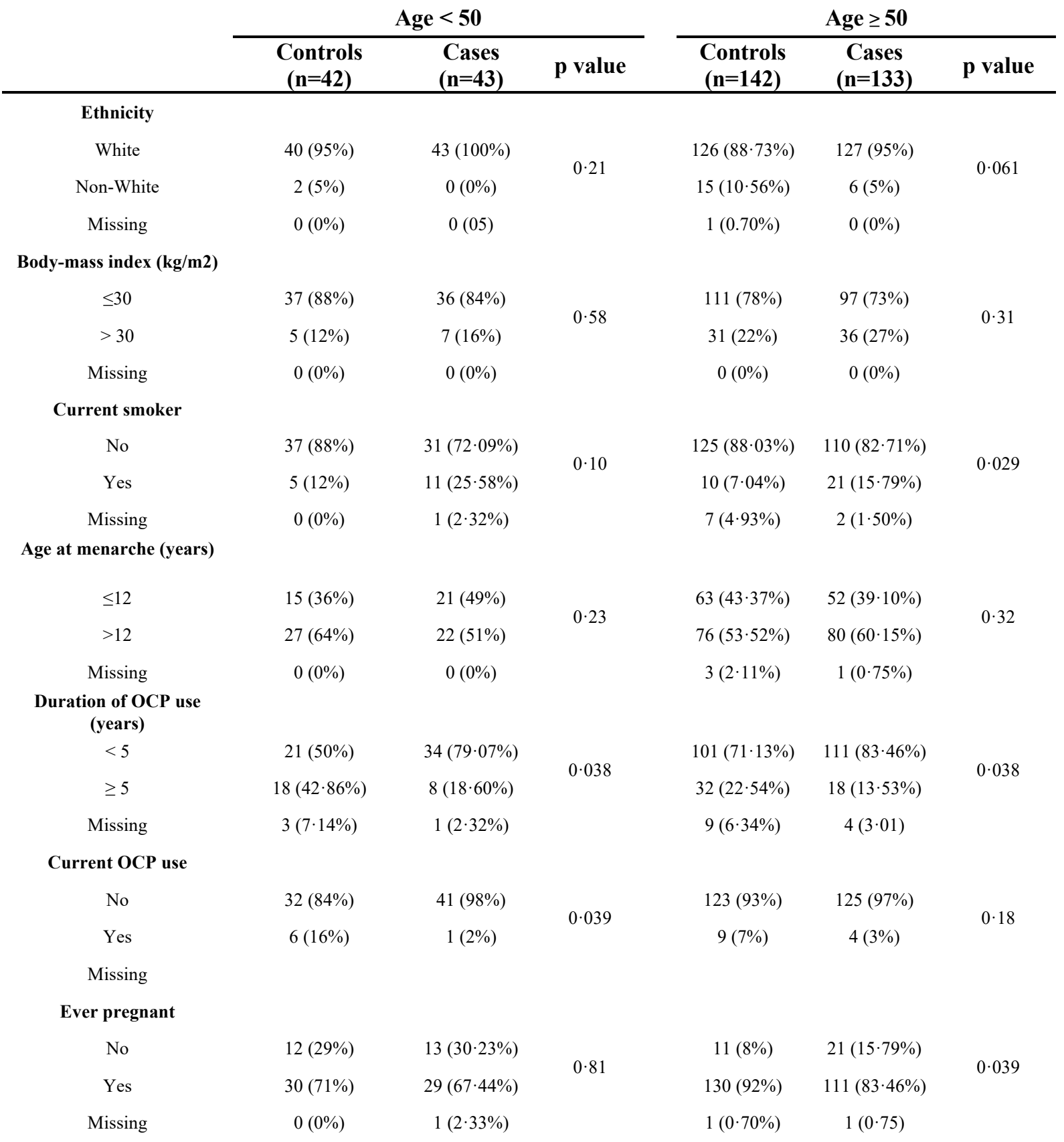




\section{Menopausal status}

Premenopausal

Postmenopausal

Missing

Ever used HRT

No
Yes
Missing
nt combined
mone use

hormone use

No

Yes

Missing

Duration of combined

hormone use (years)

$$
\begin{aligned}
& <5 \\
& \geq 5
\end{aligned}
$$

Missing

Microbiota community type

$\begin{array}{cccc}\mathrm{L} & 30(71 \%) & 20(47 \%) & \\ \mathrm{O} & 12(29 \%) & 23(53 \%) & 0 \cdot 020 \\ \text { Missing } & 0(0 \%) & 0(0 \%) & \end{array}$

$\begin{array}{ccc}11(8 \%) & 7(5 \%) & \\ 131(92 \%) & 126(95 \%) & 0 \cdot 42 \\ 0(0 \%) & 0(0 \%) & \end{array}$

$97(68 \cdot 31 \%) \quad 109(81 \cdot 96 \%)$

$44(30 \cdot 98 \%) \quad 23(17 \cdot 29 \%)$

$0 \cdot 0080$

$1(0 \cdot 70 \%) \quad 1(0 \cdot 75 \%)$

$32(84 \%) \quad 41(98 \%)$

$0 \cdot 039$

$128(90 \cdot 14 \%) \quad 127(95 \cdot 49 \%)$

$4(2 \cdot 82 \%) \quad 2(1 \cdot 50 \%)$

$0 \cdot 46$

$10(7 \cdot 04 \%) \quad 4(3 \cdot 01 \%)$

$4(9 \cdot 52 \%) \quad 1(2 \cdot 32 \%)$

$22(52 \cdot 38 \%) \quad 33(76 \cdot 74 \%)$

$0 \cdot 011$

$97(68 \cdot 31 \%) \quad 113(84 \cdot 96 \%)$

$34(23 \cdot 94 \%) \quad 14(10 \cdot 53 \%)$

$0 \cdot 0020$

$11(7 \cdot 75 \%) \quad 6(4 \cdot 51 \%)$

$3(7 \cdot 14 \%) \quad 1(2 \cdot 32 \%)$

$(2 \cdot 32 \%)$

$58(41 \%) \quad 52(39 \%)$

$84(59 \%) \quad 81(61 \%)$ 
Table 2. Descriptive characteristics of cases and controls in the BRCA set for all covariates used in prediction models. We calculated $p$ values under a logistic regression model with a bias reduction method. The appendix shows baseline characteristics for hospital-based controls with benign gynaecological conditions ( $p$ 43) and missing values per covariate ( $\mathrm{p} 59) . \mathrm{OCP}=$ oral contraceptive pill. $\mathrm{HRT}=$ hormone replacement therapy.

\begin{tabular}{|c|c|c|c|c|c|c|}
\hline & \multicolumn{2}{|c|}{ Age $<\mathbf{5 0}$} & \multirow[b]{2}{*}{$\begin{array}{c}\mathbf{p} \\
\text { value }\end{array}$} & \multicolumn{2}{|c|}{ Age $\geq \mathbf{5 0}$} & \multirow[b]{2}{*}{ p value } \\
\hline & $\begin{array}{c}\text { Controls } \\
(n=86)\end{array}$ & $\begin{array}{c}\text { Cases } \\
(n=94)\end{array}$ & & $\begin{array}{c}\text { Controls } \\
(n=25)\end{array}$ & $\begin{array}{c}\text { Cases } \\
(n=15)\end{array}$ & \\
\hline \multicolumn{7}{|l|}{ Ethnicity } \\
\hline White & $80(93 \%)$ & $84(89 \%)$ & \multirow{3}{*}{$0 \cdot 40$} & $21(84 \%)$ & $12(80 \%)$ & \multirow{3}{*}{$0 \cdot 72$} \\
\hline Non-White & $6(7 \%)$ & $10(11 \%)$ & & $4(16 \%)$ & $3(20 \%)$ & \\
\hline Missing & $0(0 \%)$ & $0(0 \%)$ & & $0(0 \%)$ & $0(0 \%)$ & \\
\hline \multicolumn{7}{|c|}{ Body-mass index $(\mathrm{kg} / \mathrm{m} 2)$} \\
\hline$\leq 30$ & $78(91 \%)$ & $79(84 \%)$ & \multirow{3}{*}{$0 \cdot 19$} & $22(88 \%)$ & $12(80 \%)$ & \multirow{3}{*}{$0 \cdot 48$} \\
\hline$>30$ & $8(9 \%)$ & $15(16 \%)$ & & $3(12 \%)$ & $3(20 \%)$ & \\
\hline Missing & $0(0 \%)$ & $0(0 \%)$ & & $0(0 \%)$ & $0(0 \%)$ & \\
\hline \multicolumn{7}{|c|}{ Current smoker } \\
\hline No & $77(89 \cdot 53 \%)$ & $86(91 \%)$ & \multirow{3}{*}{$0 \cdot 83$} & $23(92 \%)$ & $12(86 \%)$ & \multirow{3}{*}{$0 \cdot 51$} \\
\hline Yes & $8(9 \cdot 30 \%)$ & $8(9 \%)$ & & $2(8 \%)$ & $2(14 \%)$ & \\
\hline Missing & $1(1 \cdot 16 \%)$ & $0(0 \%)$ & & $0(0 \%)$ & $0(0 \%)$ & \\
\hline \multicolumn{7}{|c|}{ Age at menarche (years) } \\
\hline$\leq 12$ & $40(47 \%)$ & $40(42 \cdot 55 \%)$ & \multirow{3}{*}{$0 \cdot 69$} & $10(40 \%)$ & $6(40 \%)$ & \multirow{3}{*}{0.93} \\
\hline$>12$ & $46(53 \%)$ & $52(55 \cdot 32 \%)$ & & $14(56 \%)$ & $9(60 \%)$ & \\
\hline Missing & $0(0 \%)$ & $2(2 \cdot 13 \%)$ & & $1(4 \%)$ & $0(0 \%)$ & \\
\hline \multicolumn{7}{|c|}{ Duration of OCP use (years) } \\
\hline$<5$ & $37(43 \cdot 02 \%)$ & $35(37 \cdot 23 \%)$ & \multirow{3}{*}{$0 \cdot 32$} & $15(60 \%)$ & $6(40 \%)$ & \multirow{3}{*}{$0 \cdot 48$} \\
\hline$\geq 5$ & $41(47 \cdot 67 \%)$ & $53(56 \cdot 38 \%)$ & & $9(36 \%)$ & $6(40 \%)$ & \\
\hline Missing & $8(9 \cdot 30 \%)$ & $6(6 \cdot 38 \%)$ & & $1(4 \%)$ & $3(20 \%)$ & \\
\hline \multicolumn{7}{|c|}{ Current OCP use } \\
\hline No & $57(66 \cdot 28 \%)$ & $60(63 \cdot 83 \%)$ & \multirow{3}{*}{$0 \cdot 50$} & $19(76 \%)$ & $12(80 \%)$ & \multirow{3}{*}{$0 \cdot 11$} \\
\hline Yes & $21(24 \cdot 42 \%)$ & $28(29 \cdot 79 \%)$ & & $5(20 \%)$ & $0(0 \%)$ & \\
\hline Missing & $8(9 \cdot 30 \%)$ & $6(6 \cdot 38 \%)$ & & $1(4 \%)$ & $3(20 \%)$ & \\
\hline \multicolumn{7}{|l|}{ Ever pregnant } \\
\hline No & $39(45 \%)$ & $38(40 \%)$ & \multirow{2}{*}{$0 \cdot 51$} & $2(8 \%)$ & $0(0 \%)$ & \multirow{2}{*}{$0 \cdot 40$} \\
\hline Yes & $47(55 \%)$ & $56(60 \%)$ & & $23(92 \%)$ & $15(100 \%)$ & \\
\hline Missing & $0(0 \%)$ & $0(0 \%)$ & & $0(0 \%)$ & $0(0 \%)$ & \\
\hline
\end{tabular}

Menopausal status 


Premenopausal
Postmenopausal
Missing

\section{Ever used HRT}

No

Current combined hormone use

No
Yes

$$
\text { Missing }
$$

Duration of combined hormone use (years)

$\quad<5$
$\geq 5$
Missing

Microbiota community type

\begin{tabular}{|c|c|c|c|c|c|c|}
\hline $\mathrm{L}$ & $77(90 \%)$ & $70(74 \%)$ & $0 \cdot 0090$ & $10(40 \%)$ & $6(40 \%)$ & 0.99 \\
\hline $\mathrm{O}$ & $9(10 \%)$ & $24(26 \%)$ & & $15(60 \%)$ & $9(60 \%)$ & \\
\hline Missing & $0(0 \%)$ & $0(0 \%)$ & & $0(0 \%)$ & $0(0 \%)$ & \\
\hline
\end{tabular}

\begin{tabular}{|c|c|c|c|c|}
\hline $86(100 \%)$ & $88(94 \%)$ & & $6(24 \%)$ & $3(20 \%)$ \\
\hline $0(0 \%)$ & $6(6 \%)$ & & $19(76 \%)$ & $12(80 \%)$ \\
\hline $0(0 \%)$ & $0(0 \%)$ & & $0(0 \%)$ & $0(0 \%)$ \\
\hline
\end{tabular}

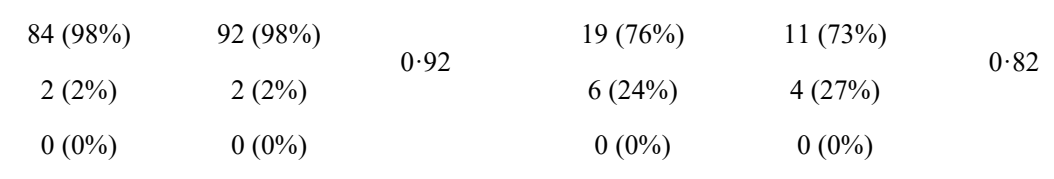

\begin{tabular}{|c|c|c|c|c|}
\hline $69(80 \%)$ & $75(80 \%)$ & \multirow{2}{*}{$0 \cdot 94$} & $21(84 \%)$ & $15(100 \%)$ \\
\hline $17(20 \%)$ & $19(20 \%)$ & & $4(16 \%)$ & $0(0 \%)$ \\
\hline $0(0 \%)$ & $0(0 \%)$ & & $0(0 \%)$ & $0(0 \%)$ \\
\hline
\end{tabular}

\begin{tabular}{|c|c|c|c|c|}
\hline $51(59 \%)$ & $53(56 \%)$ & \multirow{2}{*}{$0 \cdot 69$} & $17(68 \%)$ & $10(67 \%)$ \\
\hline $35(41 \%)$ & $41(44 \%)$ & & $8(32 \%)$ & $5(33 \%)$ \\
\hline $0(0 \%)$ & $0(0 \%)$ & & $0(0 \%)$ & $0(0 \%)$ \\
\hline
\end{tabular}




\section{Supplementary appendix}

Nuno R. Nené PhD, Daniel Reisel PhD, Andreas Leimbach PhD, Dorella Franchi MD, Allison Jones BSc, Iona Evans PhD, Susanne Knapp PhD, Andy Ryan PhD, Shohreh Ghazali MSc, John F. Timms DPhil, Tobias Paprotka PhD, Prof Line Bjørge PhD, Prof Michal Zikan MD, Prof David Cibula MD, Prof Nicoletta Colombo MD, Prof Martin Widschwendter MD.

Association between the cervicovaginal microbiome, $B R C A 1$ mutation status, and risk of ovarian cancer: a case-control study

In this supplementary information we provide Supplementary Figures 1, 2 and 3 and the additional Tables cited in the main text, where the logistic regression models are presented for the Ovarian Cancer and BRCA sets. The original clinical data, as well as the microbiome abundance percentages used in this work (see Methods section), will be made available upon request. 


\section{Supplementary Figures}

Supplementary Figure 1. Sum of proportions of community-type $L$ species with Age, two-dimensional fitted density of individuals. A. Controls in the OC set. B. Controls in the BRCA set. Colour bars represent density and are the same for all panels in this figure. The higher the density the closer the colour is to blue. Sum of proportions, $\mathrm{y}$-axis. Age, $\mathrm{x}$-axis. Densities were estimated with the $k d e 2 d$ package in R.

A

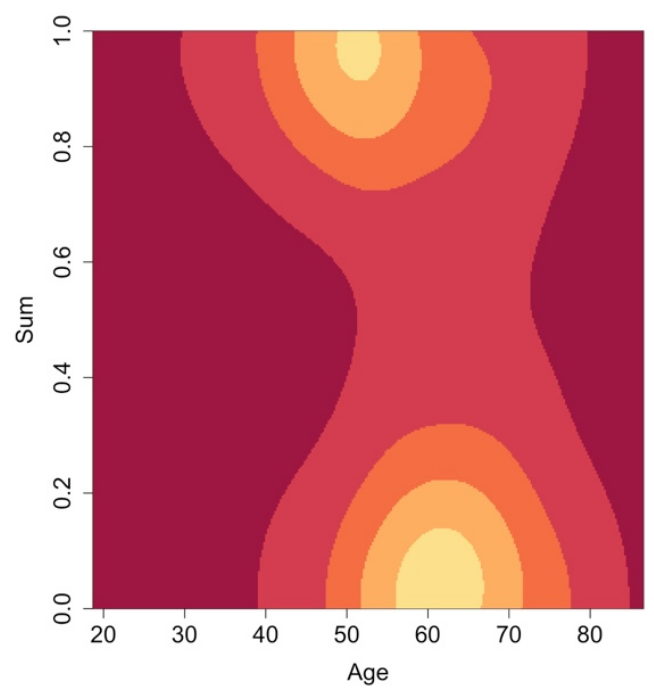

B

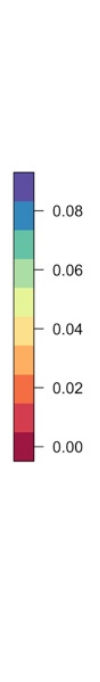

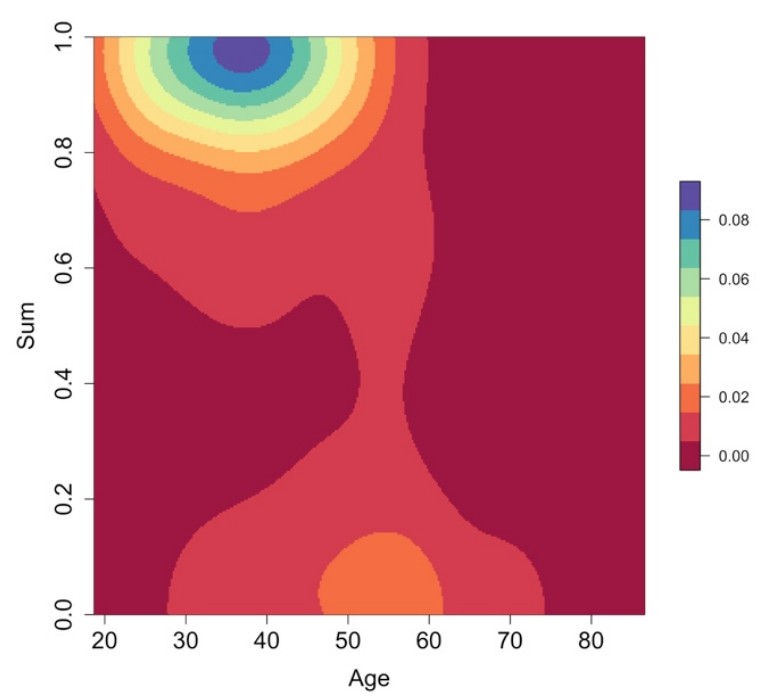


Supplementary Figure 2. Overall species abundance per subject for the Ovarian Cancer (OC) and cancer-free Control sets. Heatmap colours are proportional to abundance in each subject. The legend represents membership of community-types $\mathrm{L}$ or $\mathrm{O}$ and if the subject is a Case or a Control. $<50$ and $>50$ indicates the age of the individuals, younger or older than 50 years. $>50$ also includes subjects exactly 50 years old. SDI, Shannon Diversity Index.

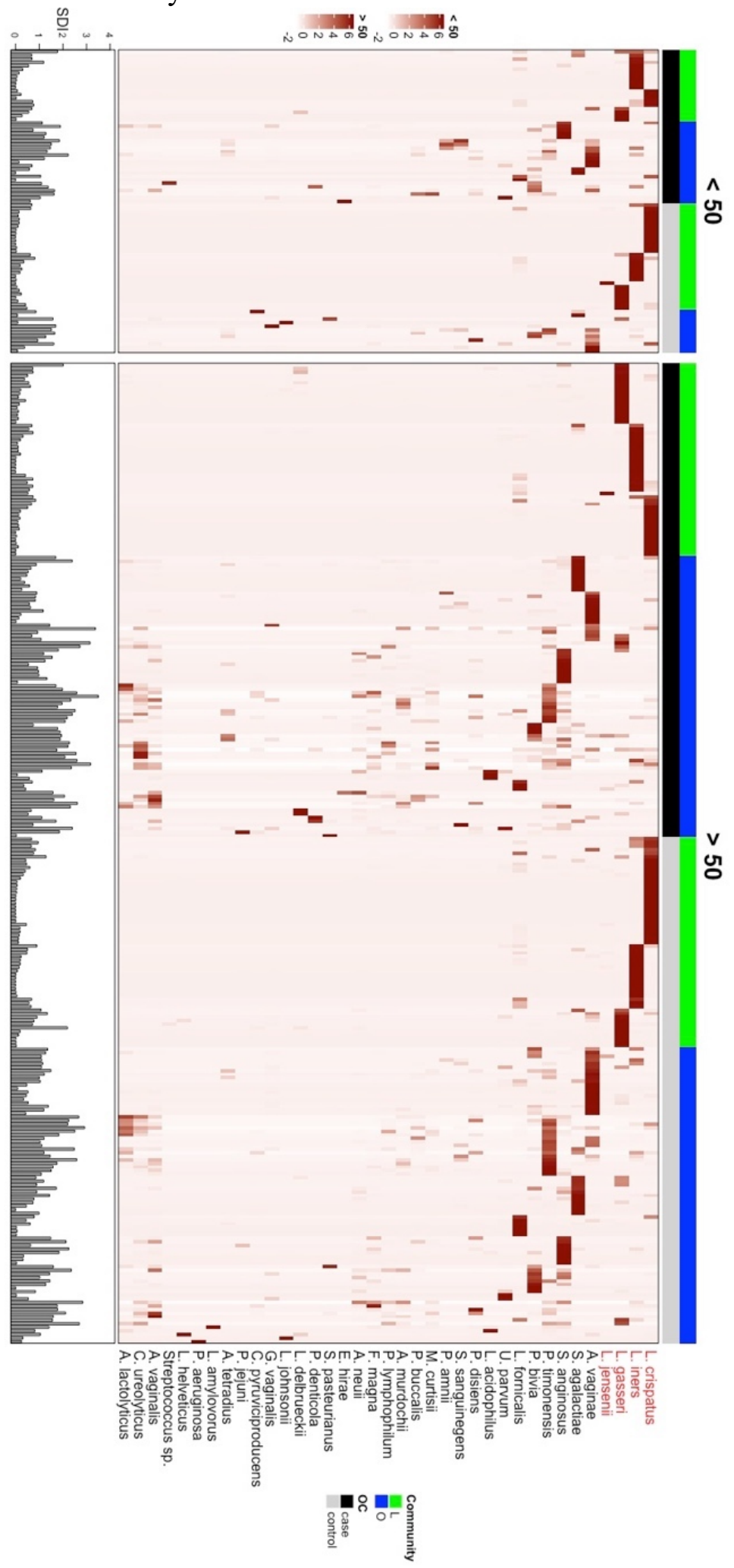


Supplementary Figure 3. Overall species abundance per subject for the BRCA1 mutation carriers and $B R C A 1$ wild type Control set. Heatmap colours are proportional to abundance in each subject. The legend represents membership of community-types $\mathrm{L}$ or $\mathrm{O}$ and if the subject is a Case or a Control. Within the mutation carrier cases, those individuals who have more than one first degree relative affected by cancer are labelled mut $>1$. Otherwise they are labelled as mut. $<50$ and $>50$ indicates the age of the individuals, younger or older than 50 years. $>50$ also includes subjects exactly 50 years old. SDI, Shannon Diversity Index. 


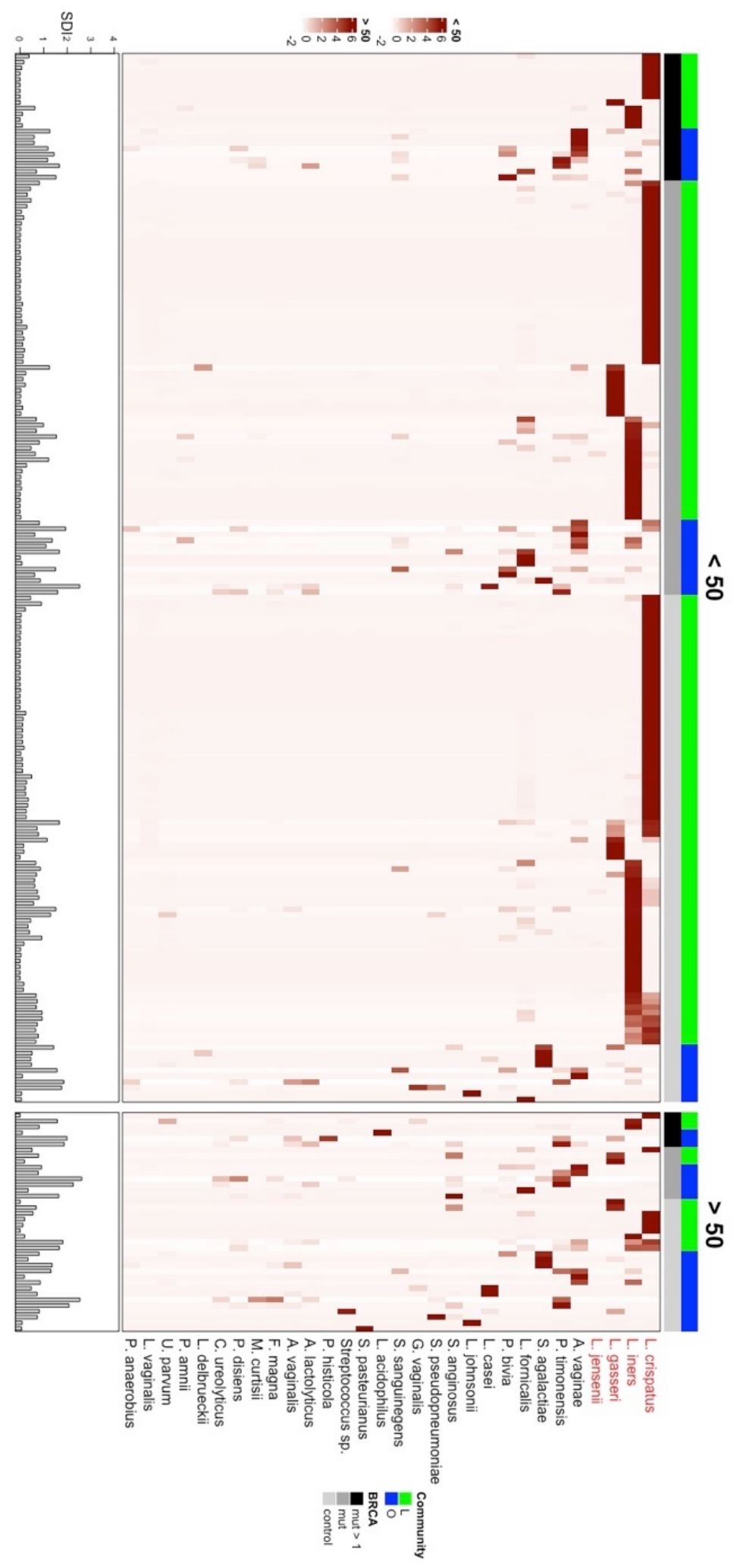




\section{Supplementary Tables}

Supplementary Table 1. Recruitment information per centre. PI- Principal Investigator.

\begin{tabular}{|c|c|c|c|}
\hline Centre & Location & PI & Numbers \\
\hline $\begin{array}{l}\text { University College London } \\
\text { Hospital }\end{array}$ & $\begin{array}{l}\text { London, } \\
\text { United Kingdom }\end{array}$ & Martin Widschwendter & 212 \\
\hline European Institute of Oncology & $\begin{array}{l}\text { Milan, } \\
\text { Italy }\end{array}$ & Nicoletta Colombo & 163 \\
\hline Charles University & $\begin{array}{l}\text { Prague, } \\
\text { Czech Republic }\end{array}$ & David Cibula \& Michal Zikan & 71 \\
\hline Bergen University Hospital & $\begin{array}{l}\text { Bergen, } \\
\text { Norway }\end{array}$ & Line Bjørge & 69 \\
\hline Bristol University Hospital & $\begin{array}{l}\text { Bristol, } \\
\text { United Kingdom }\end{array}$ & Claire Newton & $<30$ \\
\hline Munich University (LMU) & $\begin{array}{l}\text { Munich, } \\
\text { Germany }\end{array}$ & Nadia Harbeck & $<30$ \\
\hline Barts Health NHS Trust & $\begin{array}{l}\text { London, United } \\
\text { Kingdom }\end{array}$ & Ranjit Manchanda & $<30$ \\
\hline Wareham Surgery & $\begin{array}{l}\text { Wareham, } \\
\text { United Kingdom }\end{array}$ & Kate Dmochowska & $<30$ \\
\hline Portsmouth Hospital & $\begin{array}{l}\text { Portsmouth, } \\
\text { United Kingdom }\end{array}$ & Natalia Povolotskaya & $<30$ \\
\hline University Hospital Southampton & $\begin{array}{l}\text { Southampton, } \\
\text { United Kingdom }\end{array}$ & Richard Hadwin & $<30$ \\
\hline Adam Practice & $\begin{array}{l}\text { Poole, United } \\
\text { Kingdom }\end{array}$ & $\begin{array}{l}\text { Brenda Furlong \& Rebecca } \\
\text { Cutts }\end{array}$ & $<30$ \\
\hline $\begin{array}{l}\text { Central Manchester University } \\
\text { Hospital }\end{array}$ & $\begin{array}{l}\text { Manchester, } \\
\text { United Kingdom }\end{array}$ & Emma Crosbie & $<30$ \\
\hline Highcliffe Medical Centre & $\begin{array}{l}\text { Christchurch, } \\
\text { United Kingdom }\end{array}$ & Zelda Cheng & $<30$ \\
\hline Swanage Medical Centre, Dorset & $\begin{array}{l}\text { Dorset, } \\
\text { United Kingdom }\end{array}$ & Alison Page & $<30$ \\
\hline Total & & & 580 \\
\hline
\end{tabular}


Supplementary Table 2. Recruitment information per sample category for the Ovarian Cancer set.

\begin{tabular}{ccccc}
$\begin{array}{c}\text { Recruitment Centre } \\
\text { Code }\end{array}$ & $\begin{array}{c}\text { Ovarian } \\
\text { Cancer }\end{array}$ & Healthy Population Control & Benign Gynaecological Condition & Total \\
\hline C & 66 & 41 & 4 & 111 \\
A & 35 & 40 & 18 & 93 \\
D & 29 & 10 & 30 & 69 \\
B & 14 & 13 & 6 & 33 \\
I & 15 & 0 & 7 & 22 \\
G & 7 & 0 & 4 & 11 \\
K & 0 & 6 & 0 & 6 \\
H & 4 & 0 & 0 & 4 \\
E & 4 & 0 & 0 & 4 \\
L & 0 & 2 & 0 & 2 \\
J & 2 & 0 & 0 & 2 \\
N & 0 & 1 & 0 & 1 \\
F & 0 & 1 & 0 & 1 \\
M & 0 & 1 & 0 & 1 \\
\hline Total & 176 & 115 & 69 & 360 \\
\hline
\end{tabular}

Supplementary Table 3. Recruitment information per sample category for the BRCA set.

\begin{tabular}{ccccc}
$\begin{array}{c}\text { Recruitment Centre } \\
\text { Code }\end{array}$ & BRCA & Healthy Population Control & Benign Gynaecological Condition & Total \\
\hline A & 60 & 57 & 2 & 119 \\
C & 29 & 23 & 0 & 52 \\
B & 16 & 10 & 12 & 38 \\
F & 4 & 7 & 0 & 11 \\
\hline Total & 109 & 97 & 14 & $\mathbf{2 2 0}$ \\
\hline
\end{tabular}


Supplementary Table 4. Baseline characteristics for hospital-based controls.

\begin{tabular}{lcc} 
Benign control type & $\begin{array}{c}\text { Ovarian Cancer set } \\
(\mathbf{n = 6 9 )}\end{array}$ & $\begin{array}{c}\text { BRCA set } \\
(\mathbf{n}=\mathbf{1 4})\end{array}$ \\
\hline Benign adnexal cyst & $10(14 \cdot 5 \%)$ & $4(28 \cdot 6 \%)$ \\
Benign breast changes & $3(4 \cdot 3 \%)$ & $1(7 \cdot 1 \%)$ \\
Benign endometrial changes & $6(8 \cdot 7 \%)$ & $1(7 \cdot 1 \%)$ \\
Endometriosis & $3(4 \cdot 3 \%)$ & \\
Fibroid & $1(1 \cdot 4 \%)$ & \\
Ovarian Adenoma & $2(2 \cdot 9 \%)$ & \\
Ovarian Fibroma & $15(21 \cdot 7 \%)$ & $3(21 \cdot 4 \%)$ \\
Ovarian Teratoma & $3(4 \cdot 3 \%)$ & $4(28 \cdot 6 \%)$ \\
Pelvic floor dysfunction & $12(17 \cdot 4 \%)$ & \\
Unspecified gynaecological problems & $7(10 \cdot 1 \%)$ & \\
Uterine Fibroid(s) & $7(10 \cdot 1 \%)$ & $1(7 \cdot 1 \%)$ \\
\hline
\end{tabular}


Supplementary Table 5. Percentages and unadjusted p-values for all covariates used in the prediction of community-type $O$ in the Ovarian Cancer set, Age $<50$ years. $\mathrm{BMI}=$ Body-mass index $\left(\mathrm{kg} / \mathrm{m}^{2}\right) . \mathrm{OCP}=$ oral contraceptive pill. $\mathrm{HRT}=$ hormone replacement therapy. See Supplementary Table 25 for number of missing values per covariate. $p$ values were calculated under a logistic regression model with a bias reduction method (see Methods).

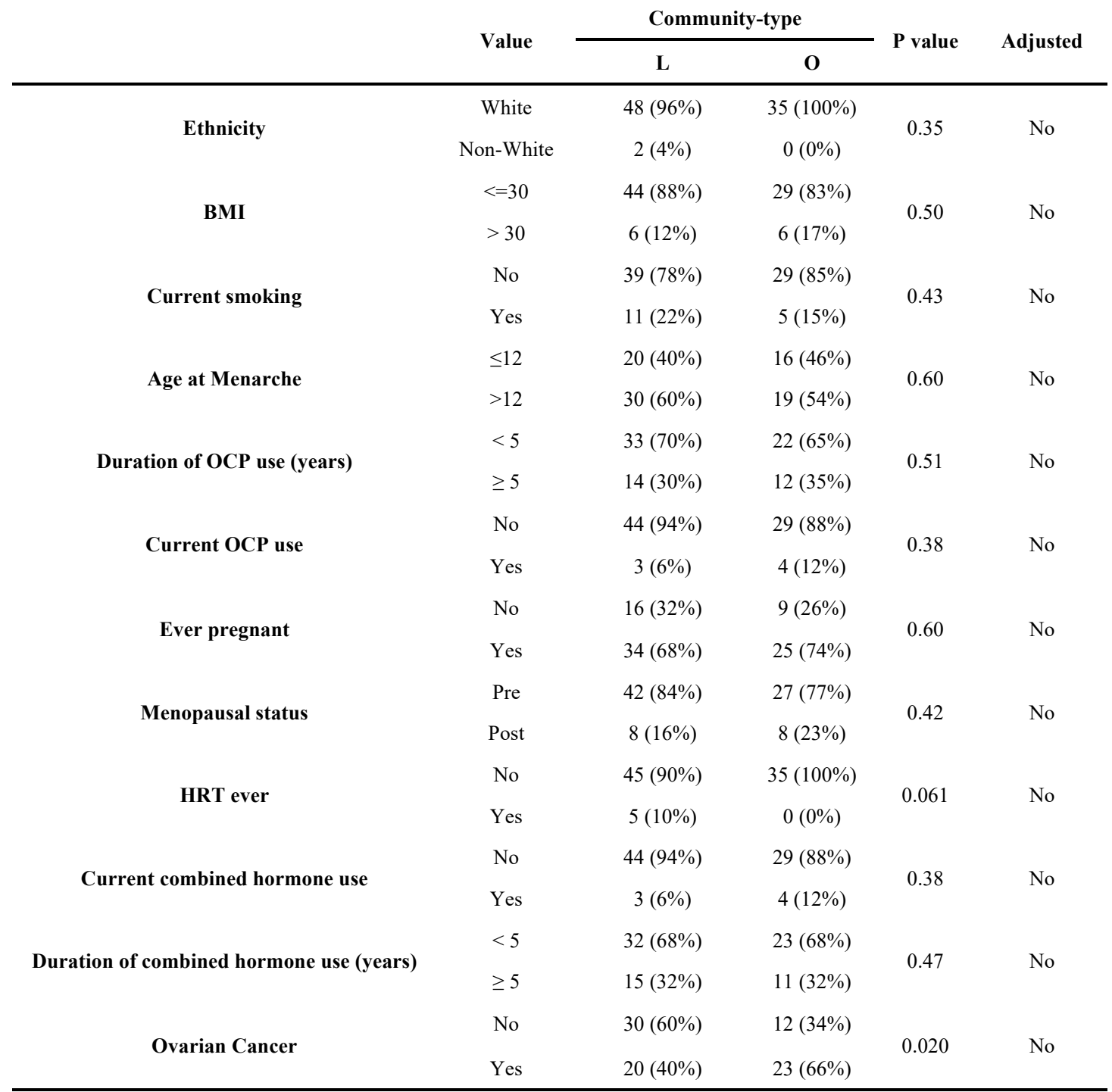


Supplementary Table 6. Unadjusted odds-ratios and p-values for all covariates used in the prediction of community-type $O$ in the Ovarian Cancer set, Age $<50$ years. $\mathrm{BMI}=$ Body-mass index $\left(\mathrm{kg} / \mathrm{m}^{2}\right) . \mathrm{OCP}=$ oral contraceptive pill. $\mathrm{HRT}=$ hormone replacement therapy. $\mathrm{p}$ values were calculated under a logistic regression model with a bias reduction method (see Methods).

\begin{tabular}{|c|c|c|c|c|c|c|}
\hline & Value & OR & CI2.5\% & CI97.5\% & $P$ value & Adjusted \\
\hline Ethnicity & White vs Non-White & 0.27 & 0.00 & 3.49 & 0.35 & No \\
\hline BMI & $<=30$ vs $>30$ & 1.51 & 0.45 & 5.03 & 0.50 & No \\
\hline Current smoking & No vs Yes & 0.64 & 0.19 & 1.91 & 0.43 & No \\
\hline Age at Menarche & $<=12$ vs $>12$ & 0.79 & 0.33 & 1.89 & 0.60 & No \\
\hline Duration of OCP use (years) & $<=5$ vs $>5$ & 1.35 & 0.55 & 3.33 & 0.51 & No \\
\hline Current OCP use & No vs Yes & 1.94 & 0.44 & 9.25 & 0.38 & No \\
\hline Ever pregnant & No vs Yes & 1.28 & 0.50 & 3.40 & 0.60 & No \\
\hline Menopausal status & Pre vs Post & 1.55 & 0.53 & 4.55 & 0.42 & No \\
\hline HRT ever & No vs Yes & 0.12 & 0.00 & 1.08 & 0.061 & No \\
\hline Current combined hormone use & No vs Yes & 1.94 & 0.44 & 9.25 & 0.38 & No \\
\hline Duration of combined hormone use (years) & $<=5$ vs $>5$ & 1.39 & 0.57 & 3.39 & 0.47 & No \\
\hline Ovarian Cancer & No vs Yes & 2.80 & 1.17 & 6.94 & 0.020 & No \\
\hline
\end{tabular}


Supplementary Table 7. Odds-ratios and p-values for all covariates used in the prediction of Case versus Control status in the Ovarian Cancer set, Age $<50$ years. $\mathrm{BMI}=$ Body-mass index $\left(\mathrm{kg} / \mathrm{m}^{2}\right) . \quad \mathrm{OCP}=$ oral contraceptive pill. $\mathrm{HRT}=$ hormone replacement therapy. $\mathrm{p}$ values were calculated under a logistic regression model with a bias reduction method (see Methods).

\begin{tabular}{|c|c|c|c|c|c|c|}
\hline & Value & OR & CI2.5\% & CI97.5\% & $P$ value & Adjusted \\
\hline Ethnicity & White vs Non-White & 0.19 & 0.00 & 2.38 & 0.21 & No \\
\hline BMI & $<=30 \mathrm{vs}>30$ & 1.40 & 0.43 & 4.85 & 0.58 & No \\
\hline Current smoking & No vs Yes & 2.49 & 0.84 & 8.20 & 0.10 & No \\
\hline Age at Menarche & $<=12$ vs $>12$ & 0.59 & 0.25 & 1.38 & 0.23 & No \\
\hline Duration of OCP use (years) & $<=5$ vs $>5$ & 0.38 & 0.15 & 0.95 & 0.038 & No \\
\hline Current OCP use & No vs Yes & 0.18 & 0.02 & 0.92 & 0.039 & No \\
\hline Ever pregnant & No vs Yes & 0.90 & 0.35 & 2.26 & 0.81 & No \\
\hline Menopausal status & Pre vs Post & 0.97 & 0.33 & 2.84 & 0.96 & No \\
\hline HRT ever & No vs Yes & 0.08 & 0.00 & 0.73 & 0.021 & No \\
\hline Current combined hormone use & No vs Yes & 0.18 & 0.02 & 0.92 & 0.039 & No \\
\hline $\begin{array}{c}\text { Duration of combined hormone use } \\
\text { (years) }\end{array}$ & $<=5$ vs $>5$ & 0.31 & 0.12 & 0.77 & 0.011 & No \\
\hline Community-type & L vs O & 2.80 & 1.17 & 6.94 & 0.020 & No \\
\hline $\begin{array}{c}\text { Community-type adjusted for } \\
\text { Current OCP use, } \\
\text { Duration of OCP use, } \\
\text { HRT ever, } \\
\text { Current combined hormone use } \\
\text { and } \\
\text { Duration of combined hormone use }\end{array}$ & L vs O & 2.84 & 1.16 & 11.23 & 0.023 & Yes \\
\hline
\end{tabular}


Supplementary Table 8. Percentages and unadjusted p-values for all covariates used in the prediction of community-type $O$ in the Ovarian Cancer set, Age $\geq 50$ years. $\mathrm{BMI}=$ Body-mass index $\left(\mathrm{kg} / \mathrm{m}^{2}\right) . \mathrm{OCP}=$ oral contraceptive pill. $\mathrm{HRT}=$ hormone replacement therapy. See Supplementary Table 25 for number of missing values per covariate. $p$ values were calculated under a logistic regression model with a bias reduction method (see Methods).

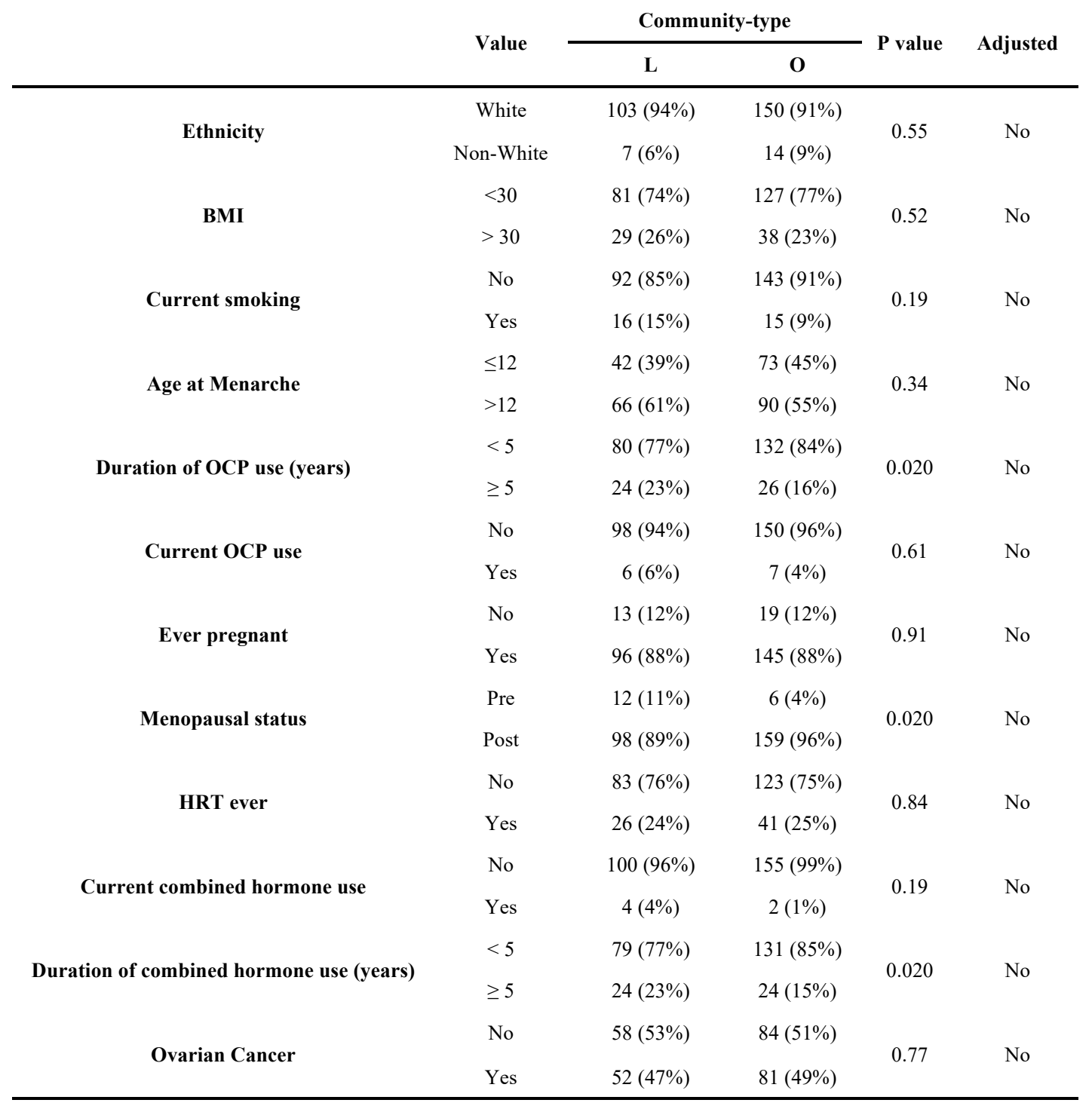


Supplementary Table 9. Unadjusted odds-ratios and p-values for all covariates used in the prediction of community-type $O$ in the Ovarian Cancer set, Age $\geq 50$ years. $\mathrm{BMI}=$ Body-mass index $\left(\mathrm{kg} / \mathrm{m}^{2}\right) . \mathrm{OCP}=$ oral contraceptive pill. $\mathrm{HRT}=$ hormone replacement therapy. $\mathrm{p}$ values were calculated under a logistic regression model with a bias reduction method (see Methods).

\begin{tabular}{|c|c|c|c|c|c|c|}
\hline & Value & OR & CI2.5\% & CI97.5\% & $P$ value & Adjusted \\
\hline Ethnicity & White vs Non-White & 1.32 & 0.54 & 3.48 & 0.55 & No \\
\hline BMI & $<=30$ vs $>30$ & 0.83 & 0.48 & 1.46 & 0.52 & No \\
\hline Current smoking & No vs Yes & 0.61 & 0.29 & 1.27 & 0.19 & No \\
\hline Age at Menarche & $<=12$ vs $>12$ & 0.79 & 0.48 & 1.29 & 0.34 & No \\
\hline Duration of OCP use (years) & $<=5 \mathrm{vs}>5$ & 0.52 & 0.30 & 0.90 & 0.020 & No \\
\hline Current OCP use & No vs Yes & 0.76 & 0.25 & 2.30 & 0.61 & No \\
\hline Ever pregnant & No vs Yes & 1.04 & 0.49 & 2.17 & 0.91 & No \\
\hline Menopausal status & Pre vs Post & 3.11 & 1.20 & 8.84 & 0.020 & No \\
\hline HRT ever & No vs Yes & 1.06 & 0.61 & 1.87 & 0.84 & No \\
\hline Current combined hormone use & No vs Yes & 0.36 & 0.06 & 1.65 & 0.19 & No \\
\hline Duration of combined hormone use (years) & $<=5$ vs $>5$ & 0.51 & 0.29 & 0.90 & 0.020 & No \\
\hline Ovarian Cancer & No vs Yes & 1.07 & 0.66 & 1.74 & 0.77 & No \\
\hline
\end{tabular}

Supplementary Table 10. Unadjusted odds-ratios and p-values for all covariates used in the prediction of Case versus Control status in the Ovarian Cancer set, Age $\geq 50$ years. $B M I=$ Body-mass index $\left(\mathrm{kg} / \mathrm{m}^{2}\right)$. $\mathrm{OCP}=$ oral contraceptive pill. HRT=hormone replacement therapy. $p$ values were calculated under a logistic regression model with a bias reduction method (see Methods).

\begin{tabular}{|c|c|c|c|c|c|c|}
\hline & Value & OR & CI2.5\% & CI97.5\% & $P$ value & Adjusted \\
\hline Ethnicity & White vs Non-White & 0.42 & 0.15 & 1.04 & 0.061 & No \\
\hline BMI & $<=30$ vs $>30$ & 1.33 & 0.77 & 2.30 & 0.31 & No \\
\hline Current smoking & No vs Yes & 2.33 & 1.09 & 5.26 & 0.029 & No \\
\hline Age at Menarche & $<=12$ vs $>12$ & 1.27 & 0.79 & 2.06 & 0.32 & No \\
\hline Duration of OCP use (years) & $<=5$ vs $>5$ & 0.56 & 0.32 & 0.97 & 0.038 & No \\
\hline Current OCP use & No vs Yes & 0.47 & 0.13 & 1.41 & 0.18 & No \\
\hline Ever pregnant & No vs Yes & 0.46 & 0.21 & 0.96 & 0.039 & No \\
\hline Menopausal status & Pre vs Post & 1.48 & 0.58 & 3.99 & 0.42 & No \\
\hline HRT ever & No vs Yes & 0.47 & 0.26 & 0.82 & 0.0080 & No \\
\hline Current combined hormone use & No vs Yes & 0.56 & 0.10 & 2.57 & 0.46 & No \\
\hline Duration of combined hormone use (years) & $<=5$ vs $>5$ & 0.40 & 0.22 & 0.71 & 0.0020 & No \\
\hline Community-type & L vs O & 1.07 & 0.66 & 1.74 & 0.77 & No \\
\hline
\end{tabular}


Supplementary Table 11. Percentages and unadjusted p-values for all covariates used in the prediction of community-type $O$ in the BRCA set, Age $<50$ years. $\mathrm{BMI}=$ Body-mass index $\left(\mathrm{kg} / \mathrm{m}^{2}\right) . \quad \mathrm{OCP}=$ oral contraceptive pill. $\mathrm{HRT}=$ hormone replacement therapy. See Supplementary Table 25 for number of missing values per covariate. $p$ values were calculated under a logistic regression model with a bias reduction method (see Methods).

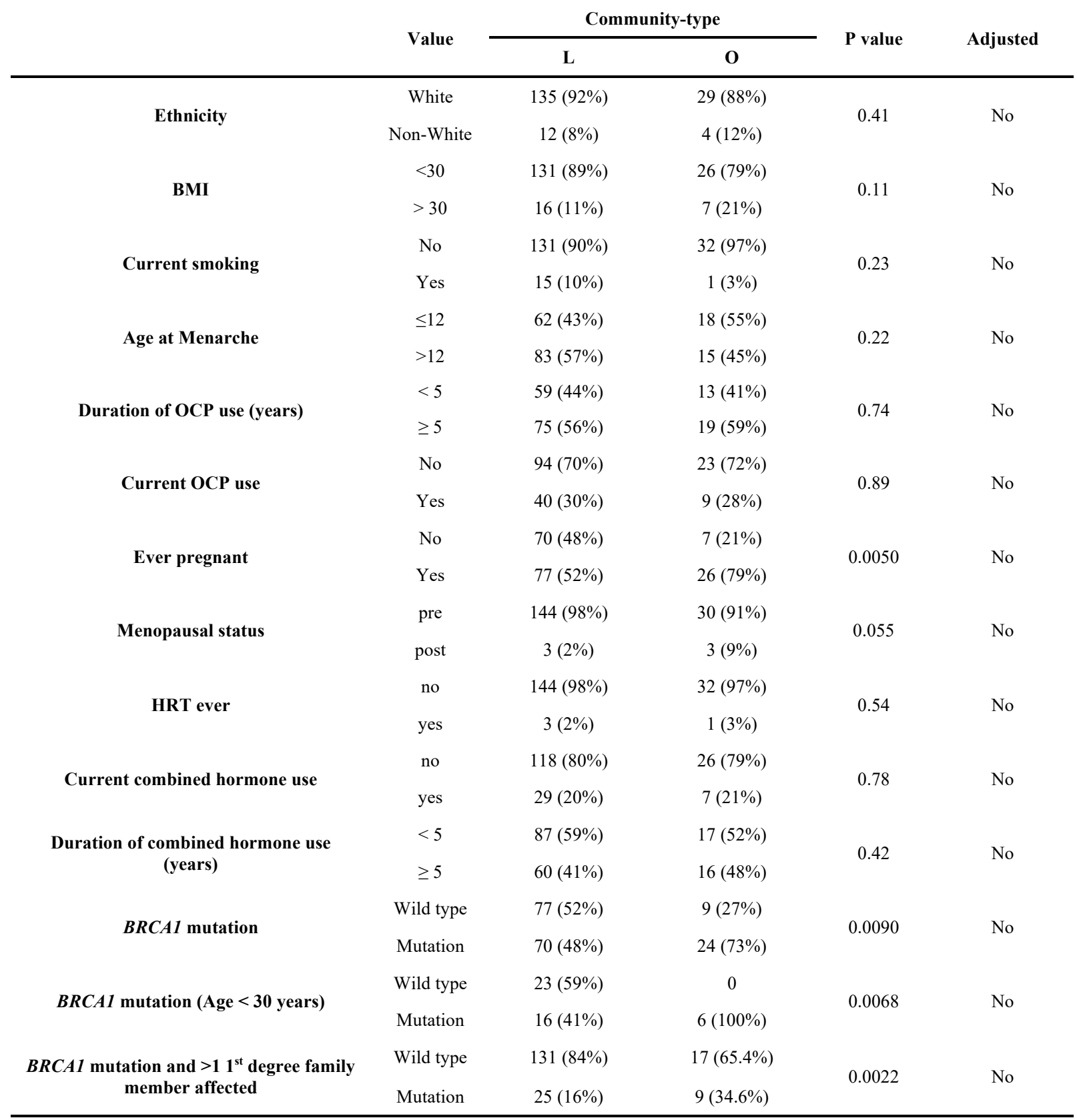


Supplementary Table 12. Percentages and unadjusted p-values for all covariates used in the prediction of community-type $O$ in the BRCA set, Age $<50$ years.

Distinction between individuals who have more than one first degree relative affected with cancer is provided. See Supplementary Table 25 for number of missing values per covariate. $p$ values were calculated under a logistic regression model with a bias reduction method (see Methods).

\begin{tabular}{|c|c|c|c|c|}
\hline & \multirow{2}{*}{ Value } & \multicolumn{2}{|c|}{ Community-type } & \multirow{2}{*}{$P$ value } \\
\hline & & $\mathbf{L}$ & $\mathbf{O}$ & \\
\hline \multirow{3}{*}{ BRCA1 mutation } & Wild type & $73(49.66 \%)$ & $9(27.273 \%)$ & \multirow{3}{*}{0.0022} \\
\hline & $\begin{array}{c}\text { Mutation and }<=11 \text { st degree family member } \\
\text { affected }\end{array}$ & $57(38.776 \%)$ & $15(45.455 \%)$ & \\
\hline & Mutation and $>11^{\text {st }}$ degree family member affected & $17(11.565 \%)$ & $9(27.273 \%)$ & \\
\hline
\end{tabular}

Supplementary Table 13. Odds-ratios and p-values for all covariates used in the prediction of community-type $\mathbf{O}$ in the BRCA set, Age $<\mathbf{5 0}$ years. $B R C A 1$ mutation (Age $<30$ ), focus on individuals with Age $<30$. An additional test was performed for individuals who have more than one $1^{\text {st }}$ degree relative affected by cancer. $\mathrm{BMI}=$ Bodymass index $\left(\mathrm{kg} / \mathrm{m}^{2}\right)$. $\mathrm{OCP}=$ oral contraceptive pill. $\mathrm{HRT}=$ hormone replacement therapy. $\mathrm{p}$ values were calculated under a logistic regression model with a bias reduction method (see Methods).

\begin{tabular}{|c|c|c|c|c|c|c|}
\hline & Value & OR & CI2.5\% & CI97.5\% & $P$ value & Adjusted \\
\hline Ethnicity & White vs Non-White & 1.65 & 0.47 & 4.93 & 0.41 & No \\
\hline BMI & $<=30$ vs $>30$ & 2.26 & 0.82 & 5.75 & 0.11 & No \\
\hline Current smoking & No vs Yes & 0.39 & 0.04 & 1.67 & 0.23 & No \\
\hline Age at Menarche & $<=12$ vs $>12$ & 0.63 & 0.29 & 1.33 & 0.22 & No \\
\hline Duration of OCP use (years) & $<=5$ vs $>5$ & 1.14 & 0.53 & 2.51 & 0.74 & No \\
\hline Current OCP use & No vs Yes & 0.94 & 0.39 & 2.13 & 0.89 & No \\
\hline Ever pregnant & No vs Yes & 3.21 & 1.40 & 8.21 & 0.0050 & No \\
\hline Menopausal status & Pre vs Post & 4.74 & 0.96 & 23.37 & 0.055 & No \\
\hline HRT ever & No vs Yes & 1.91 & 0.18 & 12.05 & 0.54 & No \\
\hline Current combined hormone use & No vs Yes & 1.14 & 0.43 & 2.71 & 0.78 & No \\
\hline $\begin{array}{l}\text { Duration of combined } \\
\text { hormone use (years) }\end{array}$ & $<=5$ vs $>5$ & 1.36 & 0.64 & 2.89 & 0.42 & No \\
\hline $\begin{array}{l}B R C A 1 \text { mutation } \\
\text { (unadjusted) }\end{array}$ & Wild type vs Mutation & 2.84 & 1.29 & 6.69 & 0.0090 & No \\
\hline $\begin{array}{c}B R C A 1 \text { mutation } \\
\text { (adjusted for pregnancy) }\end{array}$ & Wild type vs Mutation & 2.79 & 1.25 & 6.68 & 0.012 & Yes \\
\hline$B R C A 1$ mutation (Age $<30$ years) & Wild type vs Mutation & 18.52 & 1.96 & 2477.37 & 0.0068 & No \\
\hline $\begin{array}{c}B R C A 1 \text { mutation } \\
\text { and } \\
>11^{\text {st }} \text { degree family member affected }\end{array}$ & Wild type vs Mutation & 5.26 & 1.83 & 15.30 & 0.0022 & No \\
\hline
\end{tabular}


Supplementary Table 14. Odds-ratios and p-values for all covariates used in the prediction of $B R C A 1$ status in the BRCA set, Age $<50$ years. BMI=Body-mass index $\left(\mathrm{kg} / \mathrm{m}^{2}\right) . \mathrm{OCP}=$ oral contraceptive pill. $\mathrm{HRT}=$ hormone replacement therapy. $\mathrm{p}$ values were calculated under a logistic regression model with a bias reduction method (see Methods).

\begin{tabular}{|c|c|c|c|c|c|c|}
\hline & Value & OR & CI2.5\% & CI97.5\% & $P$ value & Adjusted \\
\hline Ethnicity & $\begin{array}{l}\text { White vs Non- } \\
\text { White }\end{array}$ & 1.54 & 0.56 & 4.52 & 0.40 & No \\
\hline BMI & $<=30$ vs $>30$ & 1.80 & 0.75 & 4.58 & 0.19 & No \\
\hline Current smoking & No vs Yes & 0.90 & 0.32 & 2.47 & 0.83 & No \\
\hline Age at Menarche & $<=12$ vs $>12$ & 1.13 & 0.63 & 2.04 & 0.69 & No \\
\hline Duration of OCP use (years) & $<=5$ vs $>5$ & 1.36 & 0.74 & 2.52 & 0.32 & No \\
\hline Current OCP use & No vs Yes & 1.26 & 0.65 & 2.47 & 0.50 & No \\
\hline Ever pregnant & No vs Yes & 1.22 & 0.68 & 2.20 & 0.51 & No \\
\hline Menopausal status & Pre vs Post & 12.71 & 1.46 & 1666.47 & 0.016 & No \\
\hline HRT ever & No vs Yes & 0.91 & 0.14 & 6.03 & 0.92 & No \\
\hline Current combined hormone use & No vs Yes & 1.03 & 0.50 & 2.13 & 0.94 & No \\
\hline $\begin{array}{c}\text { Duration of combined hormone use } \\
\text { (years) }\end{array}$ & $<=5$ vs $>5$ & 1.13 & 0.62 & 2.03 & 0.69 & No \\
\hline Community-type & L vs O & 2.84 & 1.29 & 6.69 & 0.0090 & No \\
\hline $\begin{array}{l}\text { Community-type adjusted for } \\
\text { Menopausal status }\end{array}$ & $\mathrm{L}$ vs $\mathrm{O}$ & 2.59 & 1.16 & 6.18 & 0.020 & Yes \\
\hline
\end{tabular}


Supplementary Table 15. Percentages and unadjusted p-values for all covariates used in the prediction of community-type $O$ in the BRCA set, Age $\geq 50$ years. $\mathrm{BMI}=$ Body-mass index $\left(\mathrm{kg} / \mathrm{m}^{2}\right) . \quad \mathrm{OCP}=$ oral contraceptive pill. HRT=hormone replacement therapy. See Supplementary Table 25 for number of missing values per covariate. $\mathrm{p}$ values were calculated under a logistic regression model with a bias reduction method (see Methods).

\begin{tabular}{|c|c|c|c|c|c|}
\hline & \multirow{2}{*}{ Value } & \multicolumn{2}{|c|}{ Community-type } & \multirow{2}{*}{$P$ value } & \multirow{2}{*}{ Adjusted } \\
\hline & & $\mathbf{L}$ & o & & \\
\hline \multirow{2}{*}{ Ethnicity } & White & $14(88 \%)$ & $19(79 \%)$ & \multirow{2}{*}{0.55} & \multirow{2}{*}{ No } \\
\hline & Non-White & $2(12 \%)$ & $5(21 \%)$ & & \\
\hline \multirow{2}{*}{ BMI } & $<30$ & $14(88 \%)$ & $20(83 \%)$ & \multirow{2}{*}{0.78} & \multirow{2}{*}{ No } \\
\hline & $>30$ & $2(12 \%)$ & $4(17 \%)$ & & \\
\hline \multirow{2}{*}{ Current smoking } & No & $14(88 \%)$ & $21(91 \%)$ & \multirow{2}{*}{0.68} & \multirow{2}{*}{ No } \\
\hline & Yes & $2(12 \%)$ & $2(9 \%)$ & & \\
\hline \multirow{2}{*}{ Age at Menarche } & $\leq 12$ & $5(33 \%)$ & $11(46 \%)$ & \multirow{2}{*}{0.46} & \multirow{2}{*}{ No } \\
\hline & $>12$ & $10(67 \%)$ & $13(54 \%)$ & & \\
\hline \multirow{2}{*}{ Duration of OCP use (years) } & $<5$ & $8(50 \%)$ & $13(65 \%)$ & \multirow{2}{*}{0.37} & \multirow{2}{*}{ No } \\
\hline & $\geq 5$ & $8(50 \%)$ & $7(35 \%)$ & & \\
\hline \multirow{2}{*}{ Current OCP use } & No & $13(81 \%)$ & $18(90 \%)$ & \multirow{2}{*}{0.47} & \multirow{2}{*}{ No } \\
\hline & Yes & $3(19 \%)$ & $2(10 \%)$ & & \\
\hline \multirow{2}{*}{ Ever pregnant } & No & $0(0 \%)$ & $2(8 \%)$ & \multirow{2}{*}{0.36} & \multirow{2}{*}{ No } \\
\hline & Yes & $16(100 \%)$ & $22(92 \%)$ & & \\
\hline \multirow{2}{*}{ Menopausal status } & Pre & $6(38 \%)$ & $3(12 \%)$ & \multirow{2}{*}{0.070} & \multirow{2}{*}{ No } \\
\hline & Post & $10(62 \%)$ & $21(88 \%)$ & & \\
\hline \multirow{2}{*}{ HRT ever } & No & $13(81 \%)$ & $17(71 \%)$ & \multirow{2}{*}{0.49} & \multirow{2}{*}{ No } \\
\hline & Yes & $3(19 \%)$ & $7(29 \%)$ & & \\
\hline \multirow{2}{*}{ Current combined hormone use } & No & $14(88 \%)$ & $22(92 \%)$ & \multirow{2}{*}{0.65} & $\mathrm{~N}$ \\
\hline & Yes & $2(12 \%)$ & $2(8 \%)$ & & 100 \\
\hline & $<5$ & $9(56 \%)$ & $18(75 \%)$ & & \\
\hline $\begin{array}{c}\text { Duration of combined hormone use } \\
\text { (years) }\end{array}$ & $\geq 5$ & $7(44 \%)$ & $6(25 \%)$ & 0.22 & No \\
\hline & No & $10(62 \%)$ & $15(62 \%)$ & OPO > > & N \\
\hline$C A T$ mutat & Yes & $6(38 \%)$ & $9(38 \%)$ & 0.99 & No \\
\hline
\end{tabular}


Supplementary Table 16. Unadjusted odds-ratios and p-values for all covariates used in the prediction of community-type $O$ in the BRCA set, Age $\geq 50$ years. $\mathrm{BMI}=$ Body-mass index $\left(\mathrm{kg} / \mathrm{m}^{2}\right) . \quad \mathrm{OCP}=$ oral contraceptive pill. HRT=hormone replacement therapy. $\mathrm{p}$ values were calculated under a logistic regression model with a bias reduction method (see Methods).

\begin{tabular}{|c|c|c|c|c|c|c|}
\hline & Value & OR & CI2.5\% & CI97.5\% & P value & Adjusted \\
\hline Ethnicity & White vs Non-White & 1.64 & 0.34 & 10.17 & 0.55 & No \\
\hline BMI & $<=30$ vs $>30$ & 1.27 & 0.24 & 8.13 & 0.78 & No \\
\hline Current smoking & No vs Yes & 0.67 & 0.09 & 4.84 & 0.68 & No \\
\hline Age at Menarche & $<=12$ vs $>12$ & 0.61 & 0.16 & 2.21 & 0.46 & No \\
\hline Duration of OCP use (years) & $<=5$ vs $>5$ & 0.56 & 0.15 & 2.04 & 0.37 & No \\
\hline Current OCP use & No vs Yes & 0.52 & 0.08 & 3.07 & 0.47 & No \\
\hline Ever pregnant & No vs Yes & 0.27 & 0.00 & 3.65 & 0.36 & No \\
\hline Menopausal status & Pre vs Post & 3.80 & 0.89 & 18.89 & 0.070 & No \\
\hline HRT ever & No vs Yes & 1.65 & 0.40 & 7.90 & 0.49 & No \\
\hline Current combined hormone use & No vs Yes & 0.64 & 0.09 & 4.61 & 0.65 & No \\
\hline Duration of combined hormone use (years) & $<=5$ vs $>5$ & 0.45 & 0.12 & 1.64 & 0.22 & No \\
\hline$B R C A 1$ mutation & $\begin{array}{l}\text { Wild type vs } \\
\text { Mutation }\end{array}$ & 0.99 & 0.28 & 3.61 & 0.99 & No \\
\hline
\end{tabular}

Supplementary Table 17. Unadjusted odds-ratios and p-values for all covariates used in the prediction of $B R C A 1$ status in the BRCA set, Age $\geq 50$ years. $\mathrm{BMI}=$ Body-mass index $\left(\mathrm{kg} / \mathrm{m}^{2}\right) . \quad \mathrm{OCP}=$ oral contraceptive pill. HRT=hormone replacement therapy. $\mathrm{p}$ values were calculated under a logistic regression model with a bias reduction method (see Methods).

\begin{tabular}{|c|c|c|c|c|c|c|}
\hline & Value & OR & CI $2.5 \%$ & CI97.5\% & $P$ value & Adjusted \\
\hline Ethnicity & White vs Non-White & 1.34 & 0.26 & 6.45 & 0.72 & No \\
\hline BMI & $<=30$ vs $>30$ & 1.80 & 0.33 & 9.77 & 0.48 & No \\
\hline Current smoking & No vs Yes & 1.88 & 0.26 & 13.62 & 0.51 & No \\
\hline Age at Menarche & $<=12$ vs $>12$ & 1.06 & 0.30 & 3.89 & 0.93 & No \\
\hline Duration of OCP use (years) & $<=5$ vs $>5$ & 1.63 & 0.42 & 6.48 & 0.48 & No \\
\hline Current OCP use & No vs Yes & 0.14 & 0.00 & 1.44 & 0.11 & No \\
\hline Ever pregnant & No vs Yes & 3.30 & 0.25 & 467.03 & 0.40 & No \\
\hline Menopausal status & Pre vs Post & 1.19 & 0.28 & 5.79 & 0.82 & No \\
\hline HRT ever & No vs Yes & 1.17 & 0.27 & 4.78 & 0.82 & No \\
\hline Current combined hormone use & No vs Yes & 0.15 & 0.00 & 1.61 & 0.13 & No \\
\hline Duration of combined hormone use (years) & $<=5$ vs $>5$ & 1.08 & 0.28 & 4.02 & 0.91 & No \\
\hline Community-type & $\mathrm{L}$ vs $\mathrm{O}$ & 0.99 & 0.28 & 3.61 & 0.99 & No \\
\hline
\end{tabular}


Supplementary Table 18. Unadjusted odds-ratios and p-values for all covariates used in the prediction of community-type $O$ in the Ovarian Cancer set, Age $<40$ years. $\mathrm{BMI}=$ Body-mass index $\left(\mathrm{kg} / \mathrm{m}^{2}\right) . \mathrm{OCP}=$ oral contraceptive pill. $\mathrm{HRT}=$ hormone replacement therapy. For this age group all subjects had the same value for the covariates 'Ethnicity', 'Menopausal status' and 'HRT ever' across all subjects. $p$ values were calculated under a logistic regression model with a bias reduction method (see Methods).

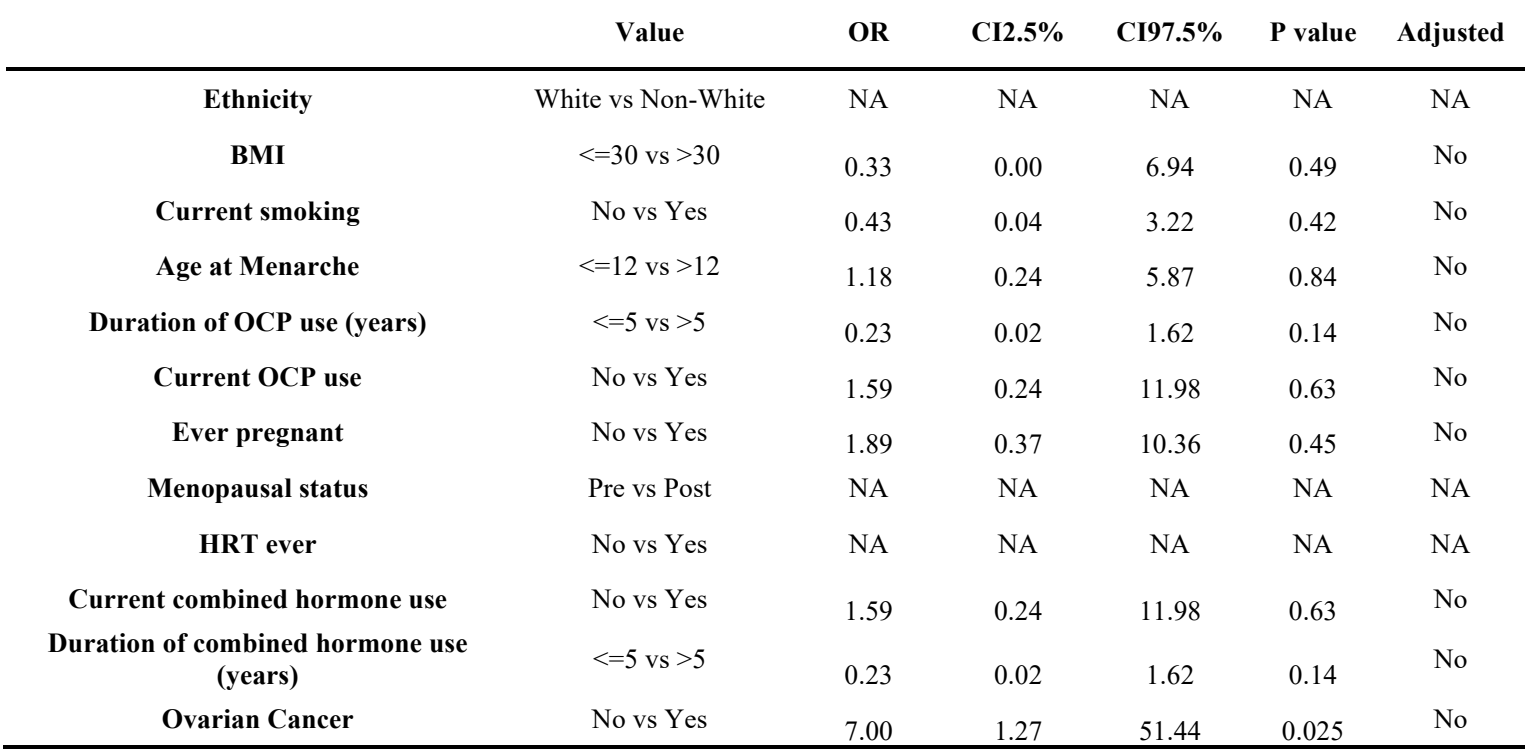

Supplementary Table 19. Unadjusted odds-ratios and p-values for all covariates used in the prediction of community-type $O$ in the Ovarian Cancer set, Age $<45$ years. $\mathrm{BMI}=$ Body-mass index $\left(\mathrm{kg} / \mathrm{m}^{2}\right) . \mathrm{OCP}=$ oral contraceptive pill. $\mathrm{HRT}=$ hormone replacement therapy. $\mathrm{p}$ values were calculated under a logistic regression model with a bias reduction method (see Methods).

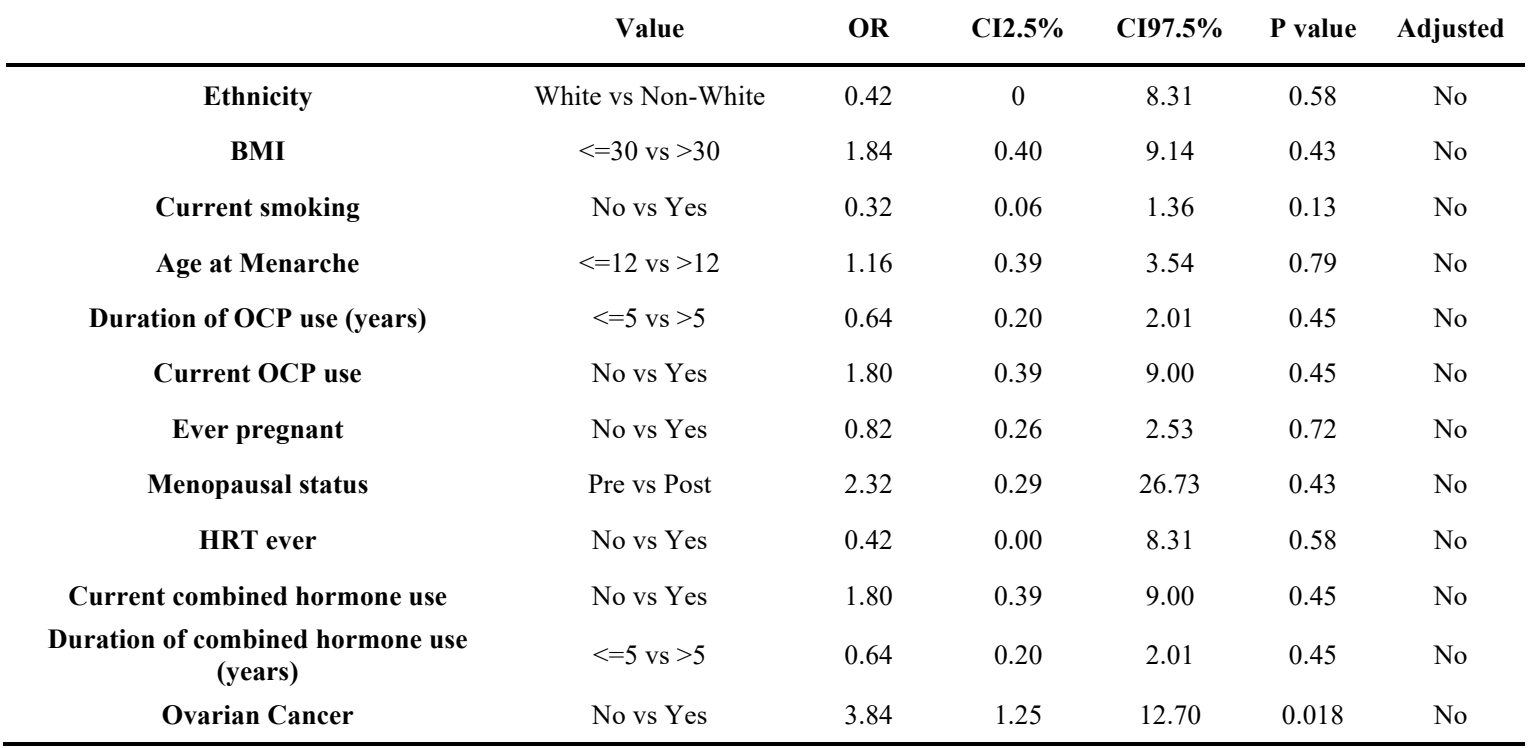


Supplementary Table 20. Odds-ratios and p-values for all covariates used in the prediction of community-type $O$ in the Ovarian Cancer set, Age $<55$ years. $\mathrm{BMI}=$ Body-mass index $\left(\mathrm{kg} / \mathrm{m}^{2}\right) . \quad \mathrm{OCP}=$ oral contraceptive pill. HRT=hormone replacement therapy. $\mathrm{p}$ values were calculated under a logistic regression model with a bias reduction method (see Methods).

\begin{tabular}{|c|c|c|c|c|c|c|}
\hline & Value & OR & CI2.5\% & CI97.5\% & P value & Adjusted \\
\hline Ethnicity & $\begin{array}{c}\text { White vs Non- } \\
\text { White }\end{array}$ & 0.99 & 0.22 & 3.86 & 0.98 & No \\
\hline BMI & $<=30$ vs $>30$ & 0.66 & 0.25 & 1.64 & 0.38 & No \\
\hline Current smoking & No vs Yes & 0.53 & 0.17 & 1.42 & 0.21 & No \\
\hline Duration of OCP use (years) & $<=5$ vs $>5$ & 1.34 & 0.67 & 2.68 & 0.41 & No \\
\hline Current OCP use & No vs Yes & 1.61 & 0.54 & 4.81 & 0.39 & No \\
\hline Ever pregnant & No vs Yes & 0.91 & 0.44 & 1.89 & 0.79 & No \\
\hline Current combined hormone use & No vs Yes & 1.59 & 0.45 & 5.62 & 0.46 & No \\
\hline Duration of combined hormone use (years) & $<=5$ vs $>5$ & 1.16 & 0.57 & 2.32 & 0.68 & No \\
\hline Ovarian Cancer & No vs Yes & 2.06 & 1.06 & 4.06 & 0.034 & No \\
\hline Ovarian Cancer adjusted for HRT ever & No vs Yes & 1.74 & 0.88 & 3.52 & 0.11 & Yes \\
\hline
\end{tabular}

Supplementary Table 21. Unadjusted odds-ratios and p-values for all covariates used in the prediction of community-type $O$ in the BRCA set, Age $<35$ years. $\mathrm{BMI}=$ Body-mass index $\left(\mathrm{kg} / \mathrm{m}^{2}\right) . \quad \mathrm{OCP}=$ oral contraceptive pill. $\mathrm{HRT}=$ hormone replacement therapy. For this age group all subjects had the same value for the covariates 'Menopausal status' and 'HRT ever'. $p$ values were calculated under a logistic regression model with a bias reduction method (see Methods).

\begin{tabular}{|c|c|c|c|c|c|c|}
\hline & Value & OR & CI2.5\% & CI97.5\% & P value & Adjusted \\
\hline Ethnicity & $\begin{array}{l}\text { White vs Non- } \\
\text { White }\end{array}$ & 0.49 & 0.00 & 4.88 & 0.61 & No \\
\hline BMI & $<=30$ vs $>30$ & 2.49 & 0.41 & 11.64 & 0.29 & No \\
\hline Current smoking & No vs Yes & 0.70 & 0.07 & 3.49 & 0.69 & No \\
\hline Age at Menarche & $<=12$ vs $>12$ & 1.05 & 0.30 & 4.04 & 0.94 & No \\
\hline Duration of OCP use (years) & $<=5$ vs $>5$ & 0.94 & 0.27 & 3.39 & 0.92 & No \\
\hline Current OCP use & No vs Yes & 2.23 & 0.64 & 8.62 & 0.21 & No \\
\hline Ever pregnant & No vs Yes & 3.16 & 0.90 & 11.57 & 0.073 & No \\
\hline Menopausal status & Pre vs Post & NA & NA & NA & NA & NA \\
\hline HRT ever & No vs Yes & NA & NA & NA & NA & NA \\
\hline Current combined hormone use & No vs Yes & 3.16 & 0.90 & 11.57 & 0.073 & No \\
\hline $\begin{array}{c}\text { Duration of combined hormone } \\
\text { use (years) }\end{array}$ & $<=5$ vs $>5$ & 1.41 & 0.39 & 4.91 & 0.59 & No \\
\hline BRCA1 mutation & $\begin{array}{c}\text { Wild type vs } \\
\text { Mutation }\end{array}$ & 4.40 & 1.14 & 24.36 & 0.031 & No \\
\hline
\end{tabular}


Supplementary Table 22. Odds-ratios and p-values for all covariates used in the prediction of community-type $O$ in the BRCA set, Age $<\mathbf{4 0}$ years. BMI=Body-mass index $\left(\mathrm{kg} / \mathrm{m}^{2}\right) . \mathrm{OCP}=$ oral contraceptive pill. HRT=hormone replacement therapy. $\mathrm{p}$ values were calculated under a logistic regression model with a bias reduction method (see Methods).

\begin{tabular}{|c|c|c|c|c|c|c|}
\hline & Value & OR & CI2.5\% & CI97.5\% & $P$ value & Adjusted \\
\hline Ethnicity & $\begin{array}{c}\text { White vs } \\
\text { Non-White }\end{array}$ & 1.14 & 0.11 & 5.91 & 0.89 & No \\
\hline BMI & $<=30$ vs $>30$ & 1.99 & 0.54 & 6.34 & 0.28 & No \\
\hline Current smoking & No vs Yes & 0.55 & 0.06 & 2.51 & 0.48 & No \\
\hline Age at Menarche & $<=12$ vs $>12$ & 1.22 & 0.46 & 3.42 & 0.70 & No \\
\hline Duration of OCP use (years) & $<=5$ vs $>5$ & 0.96 & 0.36 & 2.63 & 0.93 & No \\
\hline Current OCP use & No vs Yes & 1.33 & 0.48 & 3.55 & 0.58 & No \\
\hline Ever pregnant & No vs Yes & 3.35 & 1.25 & 9.87 & 0.016 & No \\
\hline Menopausal status & Pre vs Post & 3.10 & 0.27 & 24.68 & 0.32 & No \\
\hline HRT ever & No vs Yes & 1.65 & 0.01 & 32.13 & 0.77 & No \\
\hline Current combined hormone use & No vs Yes & 1.62 & 0.54 & 4.50 & 0.38 & No \\
\hline Duration of combined hormone use (years) & $<=5$ vs $>5$ & 1.64 & 0.62 & 4.38 & 0.32 & No \\
\hline BRCA1 mutation & $\begin{array}{l}\text { Wild type vs } \\
\text { Mutation }\end{array}$ & 3.97 & 1.38 & 13.70 & 0.0090 & No \\
\hline $\begin{array}{l}\text { BRCA1 mutation adjusted for } \\
\text { Ever pregnant }\end{array}$ & No vs Yes & 3.53 & 1.21 & 12.32 & 0.020 & Yes \\
\hline
\end{tabular}


Supplementary Table 23. Odds-ratios and p-values for all covariates used in the prediction of community-type $O$ in the BRCA set, Age $<45$ years. BMI=Body-mass index $\left(\mathrm{kg} / \mathrm{m}^{2}\right) . \mathrm{OCP}=$ oral contraceptive pill. HRT=hormone replacement therapy. $\mathrm{p}$ values were calculated under a logistic regression model with a bias reduction method (see Methods).

\begin{tabular}{|c|c|c|c|c|c|c|}
\hline & Value & OR & CI2.5\% & CI97.5\% & $P$ value & Adjusted \\
\hline Ethnicity & $\begin{array}{l}\text { White vs } \\
\text { Non-White }\end{array}$ & 1.92 & 0.45 & 6.72 & 0.35 & No \\
\hline BMI & $<=30$ vs $>30$ & 2.51 & 0.90 & 6.56 & 0.077 & No \\
\hline Current smoking & No vs Yes & 0.46 & 0.05 & 2.00 & 0.33 & No \\
\hline Age at Menarche & $<=12$ vs $>12$ & 0.77 & 0.34 & 1.70 & 0.51 & No \\
\hline Duration of OCP use (years) & $<=5 \mathrm{vs}>5$ & 1.39 & 0.61 & 3.31 & 0.44 & No \\
\hline Current OCP use & No vs Yes & 1.06 & 0.43 & 2.47 & 0.90 & No \\
\hline Ever pregnant & No vs Yes & 3.05 & 1.29 & 7.91 & 0.0099 & No \\
\hline Menopausal status & Pre vs Post & 3.34 & 0.53 & 18.01 & 0.18 & No \\
\hline HRT ever & No vs Yes & 2.73 & 0.24 & 21.30 & 0.37 & No \\
\hline Current combined hormone use & No vs Yes & 1.27 & 0.47 & 3.10 & 0.62 & No \\
\hline $\begin{array}{l}\text { Duration of combined hormone use } \\
\text { (years) }\end{array}$ & $<=5$ vs $>5$ & 1.62 & 0.73 & 3.62 & 0.24 & No \\
\hline BRCA1 mutation & No vs Yes & 3.44 & 1.46 & 8.94 & 0.0041 & No \\
\hline $\begin{array}{l}B R C A 1 \text { mutation adjusted for } \\
\text { Ever pregnant }\end{array}$ & No vs Yes & 3.24 & 1.36 & 8.49 & 0.018 & Yes \\
\hline
\end{tabular}


Supplementary Table 24. Odds-ratios and p-values for all covariates used in the prediction of community-type $O$ in the BRCA set, Age $<55$ years. BMI=Bodymass index $\left(\mathrm{kg} / \mathrm{m}^{2}\right) . \mathrm{OCP}=$ oral contraceptive pill. HRT=hormone replacement therapy. $\mathrm{p}$ values were calculated under a logistic regression model with a bias reduction method (see Methods).

\begin{tabular}{|c|c|c|c|c|c|c|}
\hline & Value & OR & CI2.5\% & CI97.5\% & P value & Adjusted \\
\hline Ethnicity & $\begin{array}{l}\text { White vs Non- } \\
\text { White }\end{array}$ & 1.86 & 0.64 & 4.91 & 0.24 & No \\
\hline BMI & $<=30$ vs $>30$ & 1.65 & 0.62 & 4.06 & 0.30 & No \\
\hline Current smoking & No vs Yes & 0.48 & 0.09 & 1.61 & 0.26 & No \\
\hline Age at Menarche & $<=12$ vs $>12$ & 0.69 & 0.35 & 1.36 & 0.28 & No \\
\hline Duration of OCP use (years) & $<=5$ vs $>5$ & 1.05 & 0.52 & 2.13 & 0.90 & No \\
\hline Current OCP use & No vs Yes & 0.73 & 0.31 & 1.59 & 0.43 & No \\
\hline Ever pregnant & No vs Yes & 3.92 & 1.77 & 9.80 & 0.00051 & No \\
\hline Menopausal status & Pre vs Post & 6.22 & 2.39 & 16.84 & 0.00022 & No \\
\hline HRT ever & No vs Yes & 2.95 & 0.64 & 12.60 & 0.16 & No \\
\hline Current combined hormone use & No vs Yes & 0.86 & 0.33 & 1.99 & 0.73 & No \\
\hline Duration of combined hormone use (years) & $<=5$ vs $>5$ & 1.23 & 0.63 & 2.41 & 0.54 & No \\
\hline$B R C A 1$ mutation & No vs Yes & 2.53 & 1.26 & 5.30 & 0.0084 & No \\
\hline $\begin{array}{c}B R C A 1 \text { mutation adjusted for } \\
\text { Ever Pregnant } \\
\text { and } \\
\text { Menopausal status } \\
\end{array}$ & No vs Yes & 2.34 & 1.40 & 10.76 & 0.022 & Yes \\
\hline
\end{tabular}


Supplementary Table 25. Number of missing values per covariate. BMI=Bodymass index $\left(\mathrm{kg} / \mathrm{m}^{2}\right)$. $\mathrm{OCP}=$ oral contraceptive pill. $\mathrm{HRT}=$ hormone replacement therapy.

\begin{tabular}{ccc} 
Variable & Ovarian Cancer set (n=360) & BRCA set (n=220) \\
\hline Ethnicity & $1(0.28 \%)$ & $0(0 \%)$ \\
AGE (years) & $0(0 \%)$ & $0(0 \%)$ \\
BMI & $0(0 \%)$ & $0(0 \%)$ \\
Current smoking & $10(2.8 \%)$ & $2(0.91 \%)$ \\
Age at Menarche (years) & $4(1.1 \%)$ & $3(1.36 \%)$ \\
Duration of OCP use (months) & $17(4.8 \%)$ & $18(8.18 \%)$ \\
Current OCP use & $19(5.3 \%)$ & $18(8.18 \%)$ \\
Ever pregnant & $3(0.83 \%)$ & $0(0 \%)$ \\
Menopausal status & $0(0 \%)$ & $0(0 \%)$ \\
HRT ever & $2(0.56 \%)$ & $0(0 \%)$ \\
Current combined hormone use & $19(5.3 \%)$ & $0(0 \%)$ \\
Duration of combined hormone use \\
(years)
\end{tabular}

Supplementary Table 26. Matching criteria for the ovarian cancer set. The numbers correspond to the cases used in the microbiome analysis. Age $\leq 5$ years $=$ within the same 5-year age bin (e.g. 50-55). Age $\leq 10$ years $=$ adjacent 10-year age bins (e.g. case in 50-55 and control in 55-60). Age $\leq 15$ years $=$ adjacent 15-year age bins. Age $\leq 20$ years $=$ adjacent 20 -year age bins. No RC means the control was selected from a different $\mathrm{RC}$. $\mathrm{RC}=$ research centre.

\begin{tabular}{cc} 
Number of cases & Matching criteria \\
\hline 105 & Menopause AND Age $\leq 5$ AND RC \\
44 & Menopause AND Age $\leq 5$ \\
21 & Menopause AND Age $\leq 10$ AND RC \\
6 & Menopause AND Age $\leq 10$ \\
\hline
\end{tabular}


Supplementary Table 27. Matching criteria for the BRCA set. The numbers correspond to the cases used in the microbiome analysis. Age $\leq 5$ years $=$ within the same 5-year age bin (e.g. 50-55). Age $\leq 10$ years $=$ adjacent 10 -year age bins (e.g. case in 50-55 and control in 55-60). Age $\leq 15$ years $=$ adjacent 15-year age bins. Age $\leq 20$ years $=$ adjacent 20 -year age bins. No RC means the control was selected from a different $\mathrm{RC} . \mathrm{RC}=$ research centre.

\begin{tabular}{|c|c|c|}
\hline Number of cases & Matching criteria & Type \\
\hline 10 & Menopause AND Age $\leq 5$ years & BRCA1 mut \\
\hline 2 & Menopause AND RC & BRCA1 mut \\
\hline 5 & $\begin{array}{c}\text { Menopause AND Age } \leq 10 \text { years AND } \\
\text { RC }\end{array}$ & BRCA1 mut \\
\hline 1 & $\begin{array}{c}\text { Menopause AND Age } \leq 15 \text { years AND } \\
\text { RC }\end{array}$ & BRCA1 mut \\
\hline 1 & $\begin{array}{c}\text { Menopause AND Age } \leq 20 \text { years AND } \\
\text { RC }\end{array}$ & BRCA1 mut \\
\hline 90 & Menopause AND Age $\leq 5$ years AND RC & BRCA1 mut \\
\hline
\end{tabular}

